\title{
Neuroprotective Effect of Didymin on Hydrogen Peroxide-Induced Injury in the Neuronal Membrane System
}

\author{
Sabrina Morelli ${ }^{\mathrm{a}}$ Antonella Piscioneri $^{\mathrm{a}}$ Simona Salerno $^{\mathrm{a}}$ \\ Mohamed B. Al-Fageeh ${ }^{c}$ Enrico Drioli ${ }^{a}$ b, d Loredana De Bartolo ${ }^{a}$ \\ a Institute on Membrane Technology, National Research Council of Italy, ITM-CNR, and ${ }^{\text {b}}$ Department of \\ Environmental and Chemical Engineering, University of Calabria, Rende, Italy; ' National Centre for Biotechnology, \\ King Abdulaziz City for Science and Technology, Riyadh, Saudi Arabia; ${ }^{d}$ WCU Energy Engineering Department, \\ Hanyang University, Seoul, Republic of Korea
}

\section{Key Words}

Didymin · Oxidative stress · Biohybrid membrane system . Antioxidants $\cdot$ Hydrogen peroxide $\cdot$ Neuronal cells

\footnotetext{
Abstract

In this study, the flavonoid didymin was administered in vitro in neuronal cells after hydrogen peroxide $\left(\mathrm{H}_{2} \mathrm{O}_{2}\right)$-induced injury (neurorescue) in order to investigate the effects of this natural molecule on cell damage in a neuronal membrane system. The results showed the effects of didymin in neuronal cells by using a polycaprolactone biodegradable membrane system as an in vitro model. Two major findings are presented in this study: first is the antioxidant property of didymin and, second, for the first time we provide evidence concerning its ability to rescue neuronal cells from oxidative damage. Didymin showed radical scavenging activities and it protected the neuronal cells against $\mathrm{H}_{2} \mathrm{O}_{2}$-induced neurotoxicity. Didymin increased cell viability, decreased intracel-
}

lular reactive oxygen species generation, stimulated superoxide dismutase, catalase and glutathione peroxidase activity in neuronal cells which were previously insulted with $\mathrm{H}_{2} \mathrm{O}_{2}$. In addition, didymin strikingly inhibited $\mathrm{H}_{2} \mathrm{O}_{2}$-induced mitochondrial dysfunctions in terms of reduction of mitochondria membrane potential and the activation of cleaved caspase- 3 , and also decreased dramatically the $\mathrm{H}_{2} \mathrm{O}_{2}$-induced phosphorylation of c-Jun $\mathrm{N}$-terminal kinase. Therefore, this molecule is capable of inducing recovery from oxidative damage, and promoting and/or restoring normal cellular conditions. Moreover, the mechanism underlying the protective effects of didymin in $\mathrm{H}_{2} \mathrm{O}_{2}$-injured neuronal cells might be related to the activation of antioxidant defense enzymes as well as to the inhibition of apoptotic features, such as p-JNK and caspase- 3 activation. These data suggest that didymin may be a potential therapeutic molecule for the treatment of neurodegenerative disorders associated with oxidative stress.

\section{KARGER}

E-Mail karger@karger.com www.karger.com/cto
(C) 2014 S. Karger AG, Basel

$1422-6405 / 14 / 1993-0184 \$ 39.50 / 0$
Dr. Sabrina Morelli

Institute on Membrane Technology, National Research Council of Italy, ITM-CNR c/o University of Calabria, Cubo $17 / \mathrm{C}$

via P. Bucci, IT-87030 Rende (Italy)

E-Mail s.morelli@itm.cnr.it 


\begin{tabular}{ll} 
Abbreviations used in this paper \\
\hline CAT & catalase \\
DCA & dynamic contact angle \\
DCF & dichlorofluorescein \\
DIV7 & 7 days in vitro \\
EMEM & minimum essential Eagle's medium \\
FITC & fluorescein \\
GPx & glutathione peroxidase \\
$\mathrm{H}_{2}$ DCF-DA & $2^{\prime}, 7^{\prime}$-dichlorofluoroscein diacetate \\
$\mathrm{H}_{2} \mathrm{O}_{2}$ & hydrogen peroxide \\
JC-1 & $5,5^{\prime}, 6,6^{\prime}$-tetrachloro-1,1',3,3'-tetraethylbenzi- \\
& midazolcarbo cyanine iodide \\
JNK & c-Jun N-terminal kinase \\
LSCM & laser scanning confocal microscopy \\
MMP & mitochondrial membrane potential \\
MTT & 3-[4,5-dimethylthiazol-2-yl]-2,5-diphenyl \\
& tetrazolium bromide \\
PCL & polycaprolactone \\
PI & propidium iodide \\
ROS & reactive oxygen species \\
SEM & scanning electron microscope \\
SOD & superoxide dismutase \\
tBHQ & tert-butylhydroquinone \\
&
\end{tabular}

\section{Introduction}

Oxidative stress is implicated in a number of neurodegenerative diseases, including Alzheimer's disease [ $\mathrm{Zhu}$ et al., 2007], Parkinson's disease [Thomas, 2009], Huntington's disease [Chen, 2011] and amyotrophic lateral sclerosis [Barber et al., 2006]. Free radicals are molecules that contain one or more unpaired electrons. The most commonly formed reactive oxygen species (ROS) are oxygen radicals, such as superoxide and hydroxyl radicals, and nonfree radicals, such as hydrogen peroxide $\left(\mathrm{H}_{2} \mathrm{O}_{2}\right)$, all of which are generated in many redox processes in the human body. The generation of ROS in normal cells is tightly regulated by biological antioxidants and antioxidant enzymes. ROS induce oxidative damage in molecules such as carbohydrates, proteins, lipids and DNA. Numerous studies have implicated ROS in neurodegenerative disease [Smith et al., 2002; Halliwell, 2006]. $\mathrm{H}_{2} \mathrm{O}_{2}$ induces apoptosis in a variety of cells, including neuronal cells [Lee et al., 2008; Wang et al., 2008], and it serves as the precursor of highly reactive free radicals.

An appropriate dietary pattern that includes fruits and vegetables decreases the risk associated with oxidative stress [Hermsdorff et al., 2012]. Plants are considered the main sources of natural antioxidants because they contain abundant quantities of phenolic compounds, such as phenolic acids, flavonoids and phenolic diterpenes [Spagnuolo et al., 2012]. Citrus peels exhibit dominant antioxidant and anti-inflammatory effects, containing more bioactive compounds, such as phenolic acids, flavonoids, limonoids and fibers, than the juices. The citrus bioactive flavonoids, especially the polymethoxy flavones and flavanone glycosides, attract considerable attention for their significant biological and pharmacological activities, including antioxidative, anti-inflammatory, and antitumor effects [Vauzour et al., 2008]. Citrus bioflavonoids like hesperidin, narirutin, naringin, neohesperidin, eriocitrin, neoeriocitrin, rutin, diosmin and neoponcirin are some of the most prominent cancer-preventing agents [Meiyanto et al., 2012].

Didymin is a plant-derived, dietary flavonoid, the antioxidant and neuroprotective properties of which are not yet well characterized. The present study investigates the protective effect of didymin against $\mathrm{H}_{2} \mathrm{O}_{2}$-induced damage to the neuronal cells in a biohybrid membrane system model. Previous studies have demonstrated that semipermeable polymeric membranes in flat and hollow fiber configurations, thanks to their highly selective structural, physicochemical and transport properties, allow the successful in vitro reconstruction of neuronal tissue, reproducing a tissue model for studying metabolic diseases and drug effects [Woerly et al., 1996; Schmidt and Leach, 2003; Zhang et al., 2005; De Bartolo et al., 2008; Giusi et al., 2009; He et al., 2009; Morelli et al., 2010; Di Vito et al., 2011; Morelli et al., 2012b, c]. It was recently reported that polycaprolactone (PCL)-based membranes successfully supported outgrowth and differentiation of human neuronal cells [Morelli et al., 2012a]. The current study attempts to determine the neuroprotective effect of didymin when it is administered after the induction of cell damage (neurorescue) in an in vitro neuronal biohybrid membrane system. $\mathrm{H}_{2} \mathrm{O}_{2}$ was used to induce toxicity in neuronal cells which were cultured in a PCL membrane system. We employed the human neuroblastoma cell line SH-SY5Y as a model cell system [Pahlman et al., 1995], as these cells may differentiate into neurons whose proliferation, alignment and direction/length depend on the substrate surface characteristics [Klein et al., 1999; Yang et al., 2005]. The SH-SY5Y cell line after retinoic acid treatment acquires morphological, neurochemical and electrophysiological properties of neurons [Kaplan et al., 1993]. Different concentrations of didymin were applied for $24 \mathrm{~h}$ and cellular viability, ROS production, antioxidative defense and apoptosis were investigated. We used tert-butylhydroquinone (tBHQ), a well-known antioxidant molecule, as a reference control in order to provide 
more reliability about the antioxidant and neuroprotective effects elicited by didymin. Indeed, this study showed for the first time the ability of didymin to suppress and/ or reverse $\mathrm{H}_{2} \mathrm{O}_{2}$-induced damage in differentiated neuronal cells in a membrane system via the inhibition of intracellular ROS production by the activation of antioxidant enzymes, and consequently attenuation of c-Jun N-terminal kinase (JNK) and caspase- 3 activation and expression.

\section{Materials and Methods}

\section{Materials}

Didymin was purchased from Extrasynthese (Genay, France). $\mathrm{H}_{2} \mathrm{O}_{2}, 2^{\prime}, 7^{\prime}$-dichlorofluoroscein diacetate $\left(\mathrm{H}_{2} \mathrm{DCF}-\mathrm{DA}\right)$, PCL, 3-[4,5-dimethylthiazol-2-yl]-2,5-diphenyltetrazolium bromide (MTT), Hanks' solution, L-glutamine and other chemicals were obtained from Sigma Aldrich (Milan, Italy). Minimum essential Eagle's medium (EMEM) and fetal bovine serum were purchased from Lonza (Basel, Switzerland). F12 and secondary antibodies were purchased from Invitrogen (Milan, Italy). Neuron-specific mouse anti- $\beta$-III tubulin/TuJ1 and anti-synaptophysin antibody were obtained from Chemicon (Millipore, Milan, Italy). Penicillin and streptomycin were obtained from Biochrom AG (Berlin, Germany). Annexin V apoptosis detection kit, 5,5',6,6'-tetrachloro$1,1^{\prime}, 3,3^{\prime}$-tetraethylbenzimidazolcarbo cyanine iodide (JC-1) and anti-phospho-JNK antibody were purchased from Santa Cruz Biotechnology (Santa Cruz, Calif., USA). Caspase- 3 antibody was obtained from BD (Franklin Lakes, N.J., USA). Catalase, superoxide dismutase (SOD) and glutathione peroxidase (GPx) assay kits were purchased from Cayman Chemical Company (Ann Arbor, Mich., USA).

\section{Preparation and Characterization of PCL Membranes}

PCL biodegradable membranes were prepared in flat configuration by an inverse phase technique. PCL (Mn 70,000-90,000 by GPC) $10 \%$ (wt/wt) was dissolved in 1,4-dioxan $(100 \%)$ at $50^{\circ} \mathrm{C}$ until complete dissolution. The solution was then cast uniformly on a glass plate. Membranes were dried at room temperature until complete solvent evaporation, and then washed with distilled water.

The morphological properties of PCL membranes and precise mean pore size, pore size distribution and thickness were characterized by scanning electron microscope (SEM). Dried membrane samples were cut in cross-section, mounted with double-faced conductive adhesive tape and analyzed by SEM (ESEM FEG QUANTA 200, FEI Company, Hillsboro, Oreg., USA) in order to establish the cross-sectional structure and thickness, shape and size of the membrane pores, as well as the pore size distribution.

The wettability of the PCL membranes was characterized by means of water dynamic contact angle (DCA) measurements. The contact angle of water droplets was measured at room temperature with a CAM 200 contact angle meter (KSV Instruments Ltd, Helsinki, Finland). DCA measurements were performed under standard conditions, which take into account various parameters (e.g. temperature, cleanliness of sample, drop volume). The instrument supported by video camera and software permitted us to obtain precise drop measurements and evolution in time. At least $30 \mathrm{mea}-$ surements on different regions of PCL membrane sample were averaged for each DCA value.

Degradation properties of developed membranes were investigated by treatment with an enzymatic solution. In particular, the samples $(1.5 \times 1.5 \mathrm{~cm})$ were precisely weighted and immersed in the lysozyme solution ( $1 \mathrm{mg} / \mathrm{ml}$ in PBS $0.2 \mathrm{M}, \mathrm{pH}=7.4)$, and then incubated at $37^{\circ} \mathrm{C}$ with refreshing media every 6 days. At the end of predetermined incubation intervals, two samples per group were removed for degradation analysis, washed with distilled water and dried at room temperature to a constant weight prior to the final determination. The dissolution index was calculated as:

$$
\% S=\frac{W i-W d}{W i} \times 100,
$$

where $\mathrm{Wi}$ is the sample weight before incubation in enzymatic solution and $\mathrm{Wd}$ is the dried sample weight after dissolution test. Each test consisted of four replicate measurements.

The mechanical properties of the biodegradable membranes were determined at room temperature using a Zwick/Roell tensile testing machine. Samples of PCL membrane, in dry state, were cut into strips of $5 \times 1 \mathrm{~cm}$ and their thickness was measured using a micrometer before every determination. They were then gripped within the pneumatic grips. Grip separation was set at $3 \mathrm{~cm}$ and a testing speed of $5 \mathrm{~mm} / \mathrm{min}$ was used. Ultimate tensile strength, Young's modulus and elongation at break parameter were evaluated. Five replicates of each sample type were tested per time point.

\section{Cell Culture and Treatments}

The human neuroblastoma cell line SH-SY5Y (ICLC-IST, Genoa, Italy) was cultured in a 1:1 mixture of Ham's F12 and EMEM supplemented with $10 \%$ ( $\mathrm{vol} / \mathrm{vol}$ ) heat-inactivated fetal bovine serum, $2 \mathrm{mM}$ glutamine and $100 \mu \mathrm{g} / \mathrm{ml}$ penicillin-streptomycin. Cells were maintained in a $5 \% \mathrm{CO}_{2}$ humidified incubator at $37^{\circ} \mathrm{C}$ in $75-\mathrm{cm}^{2}$ flasks.

For cell culture experiments, SH-SY5Y were detached by means of trypsin/EDTA solution, resuspended in Ham's F12-EMEM and seeded at a concentration of $1.5 \times 10^{3} \mathrm{cells} / \mathrm{cm}^{2}$ on PCL membranes placed on the bottom of a 12 -well cell culture plate. PCL membranes were blocked using an o-ring of Teflon and in this way cells were in contact only with the membrane surface and not with polystyrene culture dishes.

After $24 \mathrm{~h}$ cells were treated with $10 \mu \mathrm{M}$ retinoic acid in order to differentiate the cell line toward a neuronal phenotype. Then the cultures were fed every 3 days. The cells were differentiated within a time frame of 7 days; therefore, the culture medium was completely replaced with fresh Ham's F12-EMEM containing $150 \mu \mathrm{M}$ of $\mathrm{H}_{2} \mathrm{O}_{2}$ to induce oxidative stress. After $24 \mathrm{~h}$ of oxidative treatment, cells were incubated for $24 \mathrm{~h}$ in medium containing various concentrations $(0.5,1,5,10,30 \mu \mathrm{M})$ of didymin. Didymin was dissolved in DMSO and diluted with culture medium to the desired concentrations. The final concentration of DMSO was $0.01 \%$ and it had no effect on the viability of differentiated neuronal cells (data not shown).

We used the nomenclature control to indicate untreated cells in the membrane system without oxidative treatment and without didymin treatment. The antioxidant molecule tBHQ $(40 \mu \mathrm{M})$ was used as a positive control. 


\section{Sample Preparation for SEM}

The morphological behavior of the neurons at 7 days in vitro (DIV7) on PCL membranes was investigated by SEM. Samples of neurons grown on PCL membranes were prepared by fixation in $2.5 \%$ glutaraldehyde, $\mathrm{pH} 7.4$ phosphate buffer, followed by postfixation in $1 \%$ osmium tetroxide and by progressive dehydration in ethanol.

\section{Cell Viability}

Cell viability was measured by using the quantitative colorimetric 3-(4,5-dimethylthiazol-2-yl)-2,5-diphenyltetrazolium bromide (MTT) assay. Cells were incubated with medium containing MTT solution $\left(5 \mathrm{mg} / \mathrm{ml}\right.$ ) for $2 \mathrm{~h}$ at $37^{\circ} \mathrm{C}$. The reaction was stopped by adding lysis buffer (10\% SDS, $0.6 \%$ acetic acid in DMSO, pH 4.7). The quantity of formazan product was directly proportional to the number of metabolically active living cells. The optical density of each well was spectrophotometrically measured at $570 \mathrm{~nm}$. Results were expressed as the percentage of the control without treatment.

\section{Measurement of Intracellular ROS Generation}

The degree of ROS generation in cells was measured using fluorescence assay with $\mathrm{H}_{2}$ DCF-DA. This nonfluorescent compound is deacetylated by intracellular esterase to form the more hydrophilic nonfluorescent reduced dye DCFH, which then reacts with ROS and is rapidly oxidized to form the highly fluorescent dichlorofluorescein (DCF). DCF is retained within the cell and can be measured to provide an index of ROS level. Therefore, this assay provides an index of cell cytosolic oxidation. Oxidation of this probe was detected by monitoring the increase in fluorescence with a laser scanning confocal microscopy (LSCM; Fluoview FV300, Olympus, Milan, Italy), using excitation sources and filters appropriate for fluorescein (FITC). In particular, to determine the effect of didymin, the differentiated neuronal cells cultured in the membrane system were treated for $24 \mathrm{~h}$ with $\mathrm{H}_{2} \mathrm{O}_{2}(150 \mu \mathrm{M})$ before incubation for $24 \mathrm{~h}$ with various concentrations $(0.5,1,5,10,30$ $\mu \mathrm{M})$ of didymin. Following treatment, the cells were loaded with $50 \mu \mathrm{M} \mathrm{H}_{2} \mathrm{DCF}-\mathrm{DA}$ at $37^{\circ} \mathrm{C}$ for $30 \mathrm{~min}$, then cells were washed twice with Hanks' salt solution, and finally the fluorescence's intensity of DCF was measured with LSCM. A quantitative analysis was performed on LSCM images of cells using Fluoview 5.0 software (Olympus). The fluorescence intensity for DCF was calculated in a series of squared areas of $235 \times 235 \mu \mathrm{m}$ of the xy axis versus the $\mathrm{z}$ axis of the acquired images. Each image is composed of 20 slices with an optical thickness of $0.5 \mu \mathrm{m}$.

Quantitative Determination of Antioxidant Defense Enzymes

The antioxidant defense induced by didymin treatment after $\mathrm{H}_{2} \mathrm{O}_{2}$ exposure was evaluated through analysis of three different antioxidant enzymes, namely catalase (CAT), SOD and GPx. Three different Cayman's assay kits were utilized for the determination of enzyme activity of SOD, CAT and GPx. The quantitative investigation was performed according to the manufacture's protocol. All experiments were performed in triplicate.

\section{Mitochondrial Membrane Potential Assay}

Mitochondrial membrane potential (MMP) in neuronal cells was analyzed using the aggregate-forming lipohilic dye JC-1. Briefly, in healthy cells, the dye JC-1 accumulates in the mitochondrial matrix and becomes a J-aggregate form, which turns fluorescent red. In unhealthy or apoptotic cells, the MMP collapses and the JC-1 cannot accumulate within the mitochondria, and in these cells JC-1 remains in the cytoplasm in a green fluorescent monomeric form. JC- 1 was stocked as $1 \mathrm{mg} / \mathrm{ml}$ DMSO solution and freshly diluted with culture medium. Cells in different treatments were loaded with JC-1 (at a final concentration of $5 \mu \mathrm{g} / \mathrm{ml}$ ) at $37^{\circ} \mathrm{C}$ for 20 min. The fluorescence intensity of both monomers and J-aggregates were measured at LSCM. JC-1 green fluorescence was visualized with Ar laser, and red fluorescence from JC-1 aggregates was detected using $\mathrm{He} / \mathrm{Ne}$ green laser. Photomultiplier settings were the same for all acquisitions with the dye. Images were acquired from randomly selected fields. For each field 20 optical slices were taken along the optical axis at $0.75-\mu \mathrm{m}$ intervals. The MMP of neuronal cells in each treatment group was calculated as the red/green fluorescence intensity ratio and a quantitative analysis was performed on confocal images of cells by using Fluoview 5.0 software.

\section{Annexin V Apoptosis Detection}

The apoptosis of cells was investigated by Annexin $\mathrm{V}$ apoptosis detection kit according to the manufacturer's protocol by using LSCM. Normal viable cells in culture are negative for both Annexin V-FITC and propidium iodide (PI). Cells that are induced to undergo apoptosis are positive for Annexin V FITC and negative for PI. Both cells in later stages of apoptosis and necrotic cells are positive for Annexin V-FITC and PI.

The differentiated neuronal cells were rinsed with PBS and assay buffer. Then, Annexin V-FITC and PI were added to each sample. After the incubation of cells for $15 \mathrm{~min}$ at room temperature in the dark, the fluorescence's intensity of Annexin V-FITC and of PI was valued with LSCM and a quantitative analysis was performed on confocal images of cells by using Fluoview 5.0 software.

\section{Immunostaining of Neuronal Cells}

The differentiation of SH-SY5Y cells toward a neuronal phenotype at DIV7 on PCL membranes was investigated by observing them at LCSM after the immunostaining of neuronal cytoskeleton marker protein, $\beta I I I$-tubulin and synaptic vesicles marker, synaptophysin. In particular, neuronal cells were rinsed with PBS, fixed for $15 \mathrm{~min}$ with paraformaldehyde (4\%), permeabilized for $10 \mathrm{~min}$ with $0.25 \%$ Triton X-100 and subsequently blocked for $30 \mathrm{~min}$ with $1 \%$ BSA at room temperature. To visualize $\beta$ III-tubulin and synaptophysin, a polyclonal anti- $\beta$ III-tubulin (1:100) and an antisynaptophysin (1:400) were used, respectively. Primary antibodies were incubated overnight at $4^{\circ} \mathrm{C}$ and secondary antibodies for 60 min at room temperature. Nucleic acids were counterstained with DAPI (200 ng/ml). Finally, samples were rinsed, mounted and observed with an LCSM.

The expression levels of caspase-3 and phospho-JNK were examined by immunofluorescence technique using rabbit anti-caspase-3 antibody (1:250) and mouse anti-phospho-JNK (Thr183/ Tyr 185) antibody (1:250), respectively. The numbers of caspase-3 and JNK-positive nuclei (apoptotic) and DAPI-stained (total) nuclei were quantified for the different treatments. The apoptotic rate was assessed by the ratio of apoptotic nuclei over total nuclei counted at different culture conditions.

\section{Statistical Analysis}

The statistical significance of the experimental results was calculated using ANOVA test followed by the Bonferroni $t$ test $(\mathrm{p}<$ 0.05). 
Table 1. PCL membrane properties

\begin{tabular}{lc}
\hline Thickness, $\mu \mathrm{m}$ & $8 \pm 1$ \\
Mean pore diameter, nm & 22 \\
Water DCA, ${ }^{\circ}$ & \\
$\theta_{\text {adv }}$ & $78 \pm 3$ \\
$\theta_{\text {rec }}$ & $51 \pm 5$ \\
E, MPa & $208 \pm 28$ \\
$\varepsilon, \%$ & $321 \pm 100$ \\
UTS, MPa & $20 \pm 3.6$ \\
S, \% & $45 \pm 2$ \\
\hline
\end{tabular}

$\theta_{\mathrm{adv}}=$ Advancing contact angle; $\theta_{\mathrm{rec}}=$ receding contact angle; $\mathrm{E}=$ Young's modulus; $\varepsilon=$ elongation at break; UTS = ultimate tensile strength; $\mathrm{S}=$ dissolution index after 6 months.

\section{Results}

Differentiation of SH-SY5Y Cells towards Neuronal Phenotype in the PCL Membrane System

Membrane properties are decisive for cell-material interactions because they influence cell morphology through cytoskeletal organization, as well as neuronal phenotype and functions. Many studies have proved that the physicochemical properties of the membrane, namely hydrophilicity/hydrophobicity, surface energy and charge, at the interface with cells, greatly influence the neuronal cell attachment and outgrowth on the material. PCL membranes have a moderate hydrophilic character with advanced contact angle values of $78 \pm 3^{\circ}$, as demonstrated by the DCA values (table 1). The dissolution behavior of PCL membranes was very slow, although it increased with time, reaching values of $45 \pm 2 \%$ after 6 months. Topography, mechanical and tensile properties of the materials are also essential and it is necessary to take them into account when analyzing the cell response to a surface. PCL membranes have moderate stiffness in terms of ultimate tensile strength, Young's modulus and elongation at break parameter. All the data regarding matrix stiffness are reported in table 1.

The differentiation of the SH-SY5Y cell line towards the neuronal phenotype was investigated by observing morphological features and the pattern distribution of specific neuronal markers. Confocal laser micrographs of differentiated neuronal cells at DIV7 on PCL membranes, reported in figure $1 c, d$, clearly indicate that cells were differentiated showing a neuronal-like phenotype characterized by a spread cell body with a wide extension of their neuritic processes. Moreover, cells are connected to each other to form a neuronal network which is important for neuronal-specific functions.

The acquired neuronal morphology was strongly evidenced by the positive staining for $\beta$-III tubulin (fig. 1c), which is a cytoskeletal protein present in the soma and in all neuronal processes, and for synaptophysin (fig. 1d), which is a marker of synapse formation. The proliferating and undifferentiated SH-SY5Y cells were not able to express the specific neuronal marker proteins, as shown in figure $1 \mathrm{a}, \mathrm{b}$.

\section{Biohybrid PCL Membrane System for the in vitro Induction of Oxidative Stress}

The biohybrid membrane system constituted by differentiated neuronal cells and PCL membranes was used as a well-controlled microenvironment in which oxidative stress was induced to investigate the potential neuroprotective role of didymin. Neuronal cells in the PCL membrane system were exposed to various concentrations of $\mathrm{H}_{2} \mathrm{O}_{2}$, ranging from 50 to $200 \mu \mathrm{M}$ for $24 \mathrm{~h}$, and cell viability was assessed. As expected, the treatment with high concentrations of $\mathrm{H}_{2} \mathrm{O}_{2}$ impaired the viability of cells. The morphological observation in figure 2 a shows the reduction of cell number with increasing concentration of $\mathrm{H}_{2} \mathrm{O}_{2}$ up to the loss of neuritis and shrinkage of the cell body at a concentration of $200 \mu \mathrm{M}$. The proportional reduction of cell viability was confirmed by MTT results that validated the dose-dependent cytotoxic effect of $\mathrm{H}_{2} \mathrm{O}_{2}$ (fig. 2b). At low $\mathrm{H}_{2} \mathrm{O}_{2}$ concentrations of 50 and $100 \mu \mathrm{M}$, cell viability was $96 \pm 7$ and $85 \pm 26 \%$, respectively. Probably the endogenous defense systems of the cells are able to provide adequate protection against oxidative stress. At higher concentrations $(150-200 \mu \mathrm{M})$ there is a significant decrease in the percentage of viability. In particular, the treatment of cells with $150 \mu \mathrm{M}$ of $\mathrm{H}_{2} \mathrm{O}_{2}$ for $24 \mathrm{~h}$ decreases cell viability to $52 \pm 5 \%$ compared to the control without oxidative treatment. The concentration of $200 \mu \mathrm{M}$ proves to be lethal to the cells, causing a reduction of $67 \%$ in cell viability compared to untreated cells. This effect is due to the significant augment of ROS production when the concentration of $\mathrm{H}_{2} \mathrm{O}_{2}$ increases (fig. 2c). Considering the morphological analysis, the viability data and ROS production, the concentration of $150 \mu \mathrm{M}$ of $\mathrm{H}_{2} \mathrm{O}_{2}$ was chosen for subsequent experiments to induce the oxidative stress in neuronal cells in the PCL membrane system.

\section{Didymin Protects Neuronal Cells against Oxidative Stress}

To evaluate whether didymin alone is toxic and influences neuronal cell viability, differentiated neuronal cells 

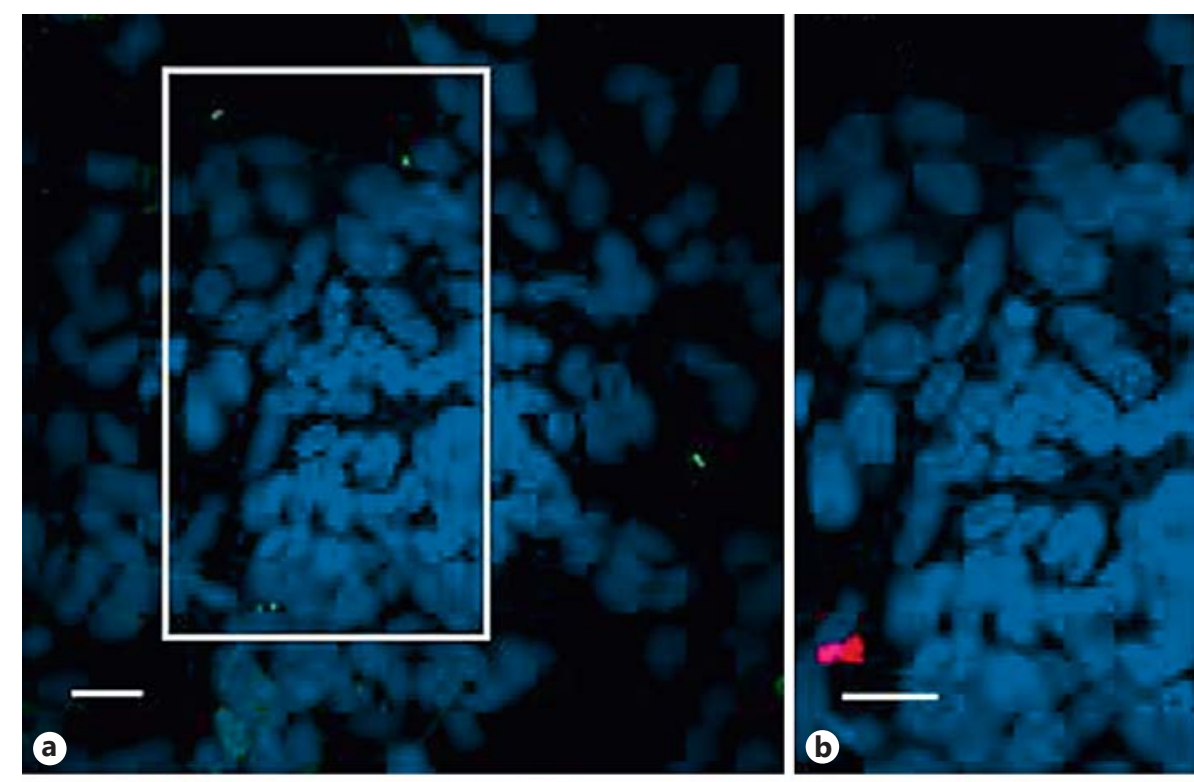

Fig. 1. The PCL membrane system elicits SH-SY5Y cell differentiation towards the neuronal phenotype. Confocal laser micrographs of proliferating SH-SY5Y cells $(\mathbf{a}, \mathbf{b})$ and differentiated neuronal cells $(\mathbf{c}, \mathbf{d})$ at DIV7 on PCL membranes. Cells were stained for BIII-tubulin (green), synaptophysin (red) and nuclei (blue). Magnified panels of synaptophysin distribution (red) in proliferating (b) and differentiated (d) cells. Scale bar $=20 \mu \mathrm{m}$.
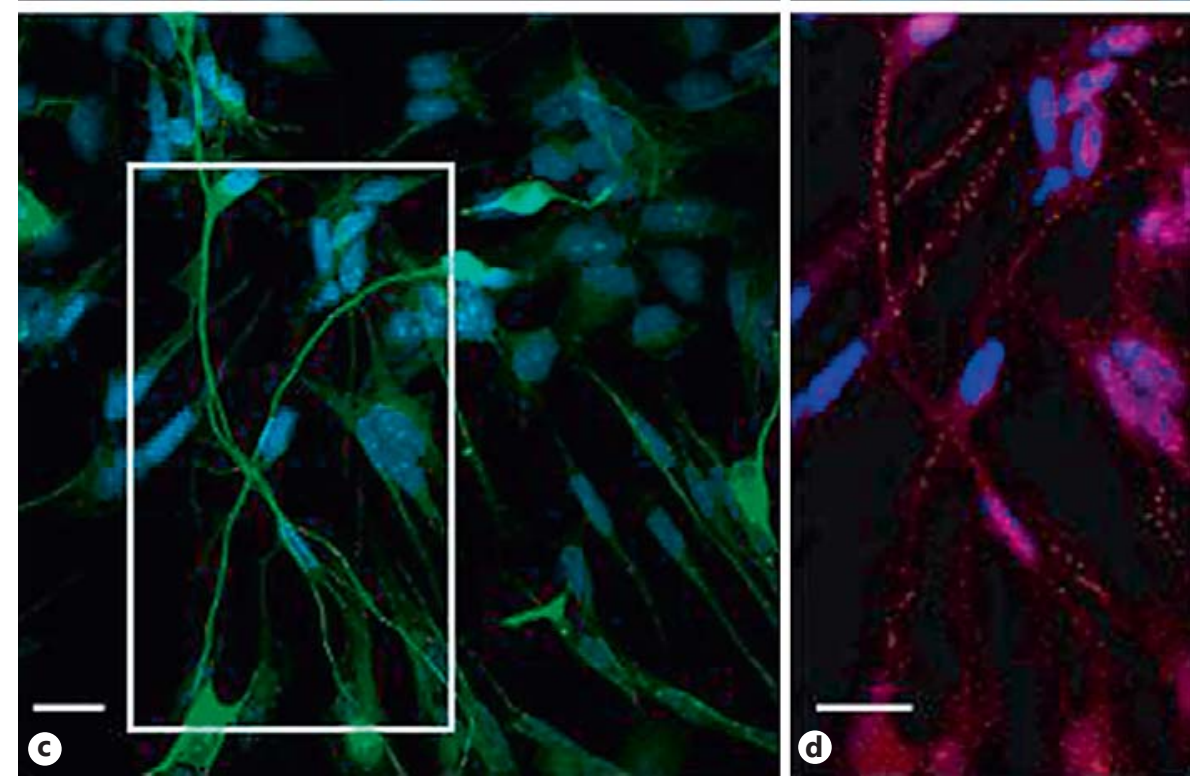

were treated with various concentrations of didymin $(0.5-30 \mu \mathrm{M})$ for $24 \mathrm{~h}$. As shown in figure 3, no significant differences were observed among cells treated with the various concentrations of didymin and the control. Cells maintained high viability levels, ranging from 86 to $100 \%$ compared to the control. Didymin at the concentrations used in our experiments is not toxic for neuronal cells. These results are in agreement with those reported by Singhal et al. [2012] demonstrating that didymin did not cause any cytotoxicity in normal cells and tissues.

To investigate the neuroprotective effect of didymin and its potential capability to induce recovery after oxi- dative stress, cells were exposed to didymin at concentrations ranging from 0.5 to $30 \mu \mathrm{M}$ before and after $\mathrm{H}_{2} \mathrm{O}_{2}(150 \mu \mathrm{M})$ insult. We also used the antioxidant molecule tBHQ $(40 \mu \mathrm{M})$ as a positive control. Both preand posttreatment with didymin significantly increased cell viability when compared to the $\mathrm{H}_{2} \mathrm{O}_{2}$-insulted samples and those without antioxidant treatment (fig. 4). The values obtained with didymin treatment are comparable with those in the presence of $\mathrm{tBHQ}$. These results demonstrate that flavonoid protects and induces the recovery from toxic damage caused by $\mathrm{H}_{2} \mathrm{O}_{2}$ in neuronal cells. 
Fig. 2. Dose-dependent toxic effects of $\mathrm{H}_{2} \mathrm{O}_{2}$ on neuronal cells in the PCL membrane system. a Morphology of neuronal cells after $24 \mathrm{~h}$ of treatment with different concentrations of $\mathrm{H}_{2} \mathrm{O}_{2}$ : control cells without any treatment (i); $100 \mu \mathrm{M} \mathrm{H}_{2} \mathrm{O}_{2}$ (ii); 150 $\mu \mathrm{M} \mathrm{H}_{2} \mathrm{O}_{2}$ (iii); $200 \mu \mathrm{M} \mathrm{H}_{2} \mathrm{O}_{2}$ (iv). Morphological studies were performed by phasecontrast microscopy. Scale bar $=50 \mu \mathrm{m}$. b Effect of $\mathrm{H}_{2} \mathrm{O}_{2}$ on cell viability after $24 \mathrm{~h}$ of treatment with different concentrations. The values expressed as average \pm SD are the means of 5 experiments and statistically significant data were evaluated according to ANOVA followed by the Bonferroni t test. ${ }^{*} \mathrm{p}<0.05$ vs. $150 \mu \mathrm{M}$ and $200 \mu \mathrm{M}$ $\mathrm{H}_{2} \mathrm{O}_{2} ;{ }^{\ddagger} \mathrm{p}<0.05$ vs. $200 \mu \mathrm{M} \mathrm{H}_{2} \mathrm{O}_{2}$. c Quantitative analysis of ROS generation by confocal microscopy. Fluorescence intensity of DCF produced at the intracellular level after $24 \mathrm{~h}$ of treatment with different concentrations of $\mathrm{H}_{2} \mathrm{O}_{2}$. The values expressed as average $\pm \mathrm{SD}$ are the means of 5 experiments and statistically significant data were evaluated according to ANOVA followed by the Bonferroni t test. ${ }^{*} \mathrm{p}<0.05$ vs. control; ${ }^{\ddagger} \mathrm{p}<0.05$ vs. other treatments.
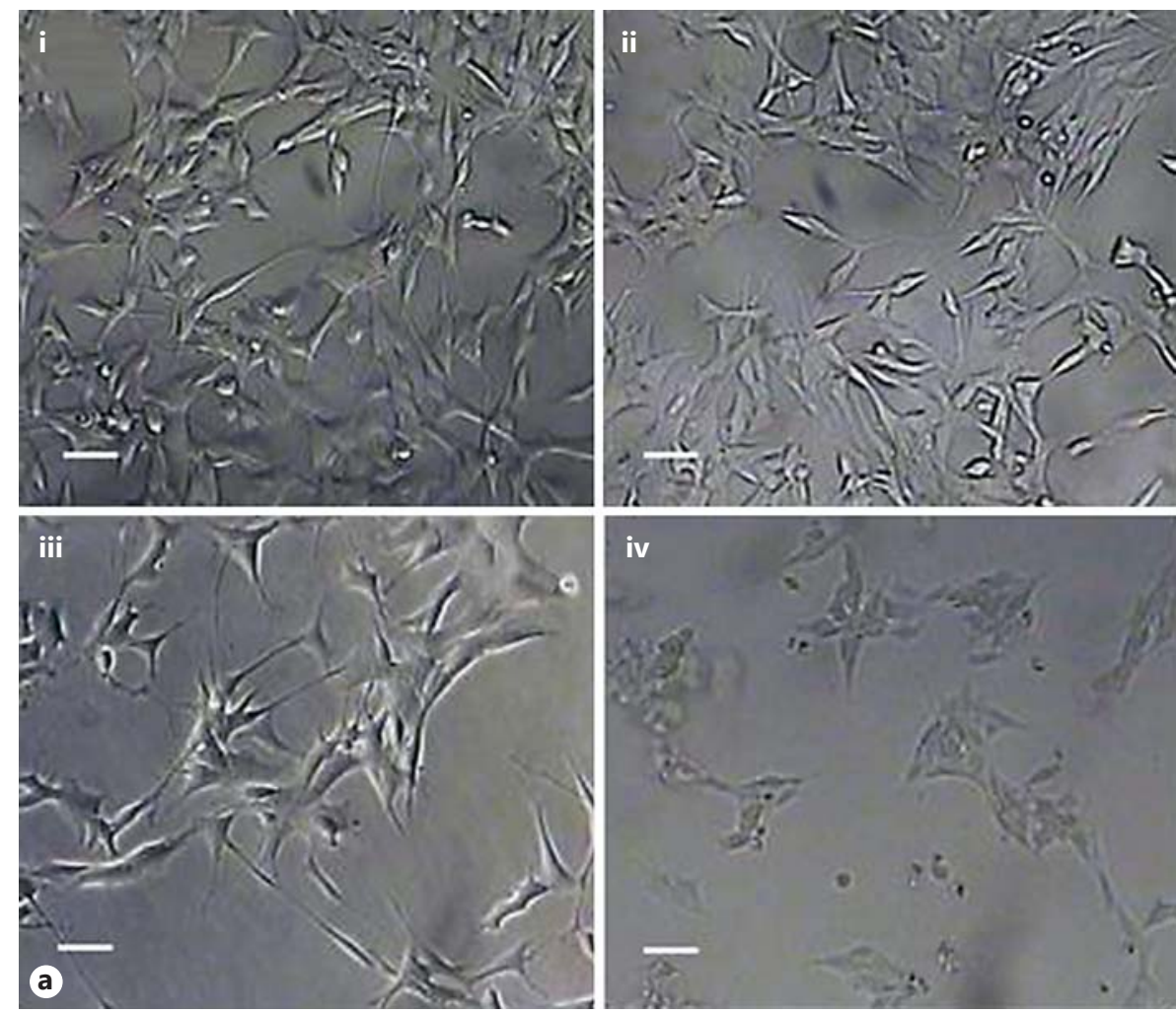

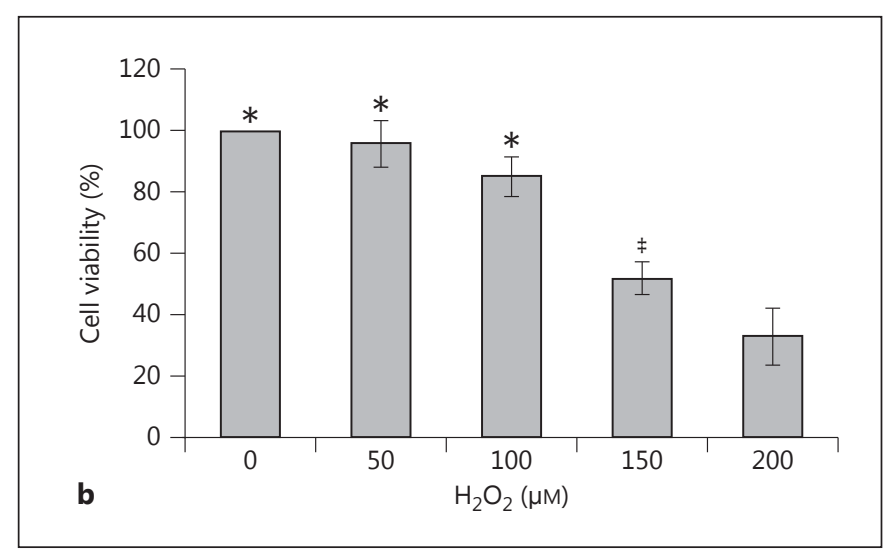

Since no significant differences were displayed in cell viability values between pre- and posttreatment, the investigation was focused on the posttreatment effect of this flavonoid.

\section{Didymin Scavenges $\mathrm{H}_{2} \mathrm{O}_{2}$-Induced ROS Production in} Neuronal Cells

The effects of didymin on $\mathrm{H}_{2} \mathrm{O}_{2}$-induced ROS production in neuronal cells were investigated using $\mathrm{H}_{2}$ DCF-DA by LSCM. The nature of the reaction between didymin and ROS in $\mathrm{H}_{2} \mathrm{O}_{2}$-treated cells is shown in figure 5. DCF

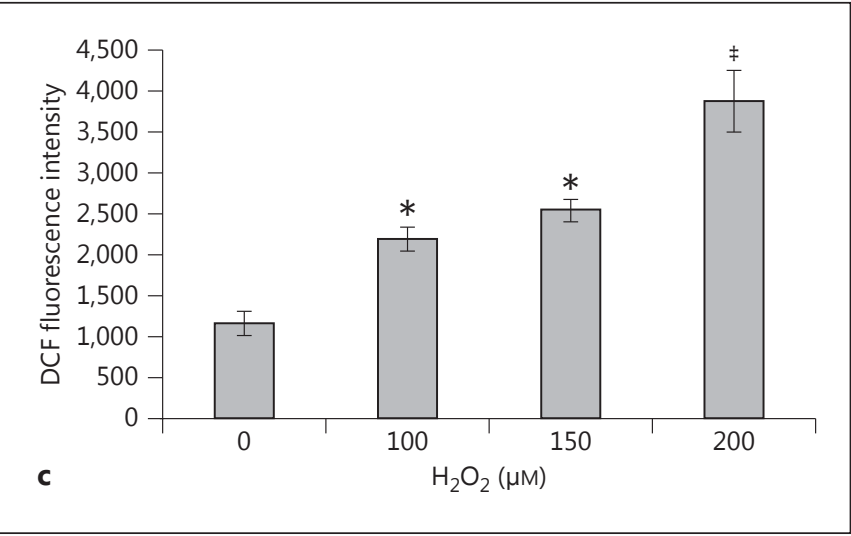

fluorescence intensity (in green) caused by $\mathrm{H}_{2} \mathrm{O}_{2}$ was significantly reduced by didymin treatment (fig. 5a). ROS levels increased upon treatment with $150 \mu \mathrm{M}$ of $\mathrm{H}_{2} \mathrm{O}_{2}$ and a decrease of free radicals production was observed after $24 \mathrm{~h}$ of didymin treatment. Didymin at a concentration of $0.5 \mu \mathrm{M}$ induced only a slight decrease in the production of ROS, as evidenced by the confocal laser micrographs (fig. 5a) in which the degree of fluorescence intensity is comparable to that observed in samples subjected to oxidative stress without antioxidant treatment. On the other hand, the concentrations of didymin in the range of 1-30 


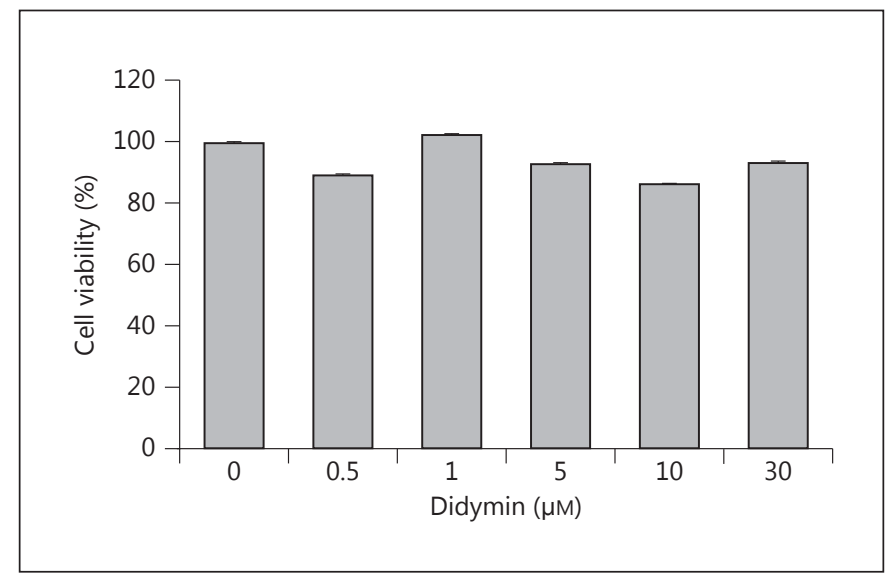

Fig. 3. Viability of neuronal cells in the PCL membrane system after $24 \mathrm{~h}$ of treatment with various concentrations of didymin.

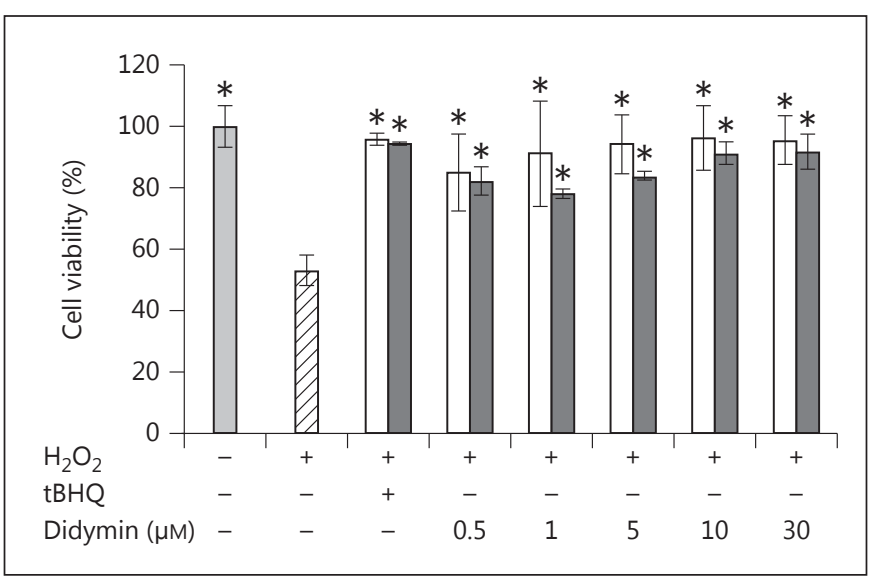

Fig. 4. Neuroprotective effect of didymin on $\mathrm{H}_{2} \mathrm{O}_{2}$-induced cytotoxicity in neuronal cells: untreated cells (grey bar), insulted cells with $\mathrm{H}_{2} \mathrm{O}_{2}$ (150 $\mu \mathrm{M}$ for $24 \mathrm{~h}$; dashed bar), pretreated cells (empty bar) and posttreated cells (full bar) with various concentrations of didymin for $24 \mathrm{~h}$. The antioxidant $\mathrm{tBHQ}$ was used as a positive control. The values expressed as average \pm SD are the means of 5 experiments and statistically significant data were evaluated according to ANOVA followed by the Bonferroni t test. ${ }^{*} \mathrm{p}<0.05$ vs. $\mathrm{H}_{2} \mathrm{O}_{2}(150 \mu \mathrm{M})$.

$\mu \mathrm{M}$ decreases ROS production significantly at levels similar to those obtained under tBHQ administration. This dose-dependent effect of didymin was further confirmed by a quantitative analysis of fluorescence intensity pattern (fig. 5b) highlighting that the in vitro didymin administration at concentrations $\geq 1 \mu \mathrm{M}$ significantly reduced the fluorescence intensity in the range of $50-60 \%$, which is related to the intracellular ROS generation.

Neuroprotective Effect of Didymin

\section{Didymin Restores Decreased Antioxidant Enzyme} Activities

We next investigated whether didymin could promote the antioxidant defense in neuronal cells. We monitored the levels of antioxidant defense enzymes of cells following $\mathrm{H}_{2} \mathrm{O}_{2}$ exposure. The activities of the antioxidant enzymes CAT (fig. 6a), SOD (fig. 6b) and GPx (fig. 6c) in cells under oxidative stress $(16.8 \pm 0.2 \mathrm{nmol} / \mathrm{min} / \mathrm{ml}, 3.5$ $\pm 0.5 \mathrm{U} / \mathrm{ml}$ and $9.5 \pm 5 \mathrm{nmol} / \mathrm{min} / \mathrm{ml}$, respectively) were decreased significantly $(\mathrm{p}<0.05)$ as compared to untreated control cells $(20.1 \pm 0.6 \mathrm{nmol} / \mathrm{min} / \mathrm{ml}, 4.1 \pm 0.2 \mathrm{U} / \mathrm{ml}$ and $38.9 \pm 4 \mathrm{nmol} / \mathrm{min} / \mathrm{ml}$, respectively).

The treatment of cells with didymin enhanced the antioxidant defense in a concentration-dependent manner. As compared to $\mathrm{H}_{2} \mathrm{O}_{2}$-damaged cells, didymin at concentrations of 10 and $30 \mu \mathrm{M}$ reversed the levels of CAT and SOD by about 1.2-fold.

Didymin already at low concentrations of $1 \mu \mathrm{M}$ significantly increased GPx activity $(34.5 \pm 1.5 \mathrm{nmol} / \mathrm{min} /$ $\mathrm{ml})$. In addition, 5,10 and $30 \mu \mathrm{M}$ didymin strongly stimulated GPx activity $(53.6 \pm 1.4,54.9 \pm 1.5$ and $54 \pm 1.5$ $\mathrm{nmol} / \mathrm{min} / \mathrm{ml}$, respectively) to reach values 1.4 -fold higher than the untreated cells. These data strongly suggested that treatment of cells with didymin restored the disintegration of the antioxidant firewall induced by $\mathrm{H}_{2} \mathrm{O}_{2}$ challenge.

\section{Didymin Effects on $\mathrm{H}_{2} \mathrm{O}_{2}$-Induced Apoptosis}

MMP reflects mitochondrial integrity and bioenergetic function, and can also be considered as an early indicator of apoptosis. In the present study, the effect of didymin on $\mathrm{H}_{2} \mathrm{O}_{2}$-induced mitochondrial function was detected via the measurement of MMP with JC-1 as a probe. The fluorescent intensity ratio value (red/green) of JC-1 in neuronal cells was significantly decreased $(\mathrm{p}<0.05)$ with the addition of $150 \mu \mathrm{M} \mathrm{H}_{2} \mathrm{O}_{2}$, demonstrating the decrease of MMP in neuronal cells (fig. 7). Treatment with concentrations of 5-30 $\mu \mathrm{M}$ reversed the $\mathrm{H}_{2} \mathrm{O}_{2}$-induced decrease of MMP.

Cells progressing through apoptosis can be monitored according to their Annexin V and PI staining pattern. Early apoptotic cells bind Annexin V but are not sensitive to intracellular staining with PI. As cells progress through apoptosis, the integrity of the plasma membrane is lost, allowing PI to penetrate and label the cells with a strong yellow-red fluorescence. The effect of didymin on $\mathrm{H}_{2} \mathrm{O}_{2}$ induced apoptosis was evaluated in neuronal cells using Annexin V/PI assay by LSCM to determine if cells were viable, apoptotic or necrotic through differences in plasma membrane integrity and permeability. Cells treated 

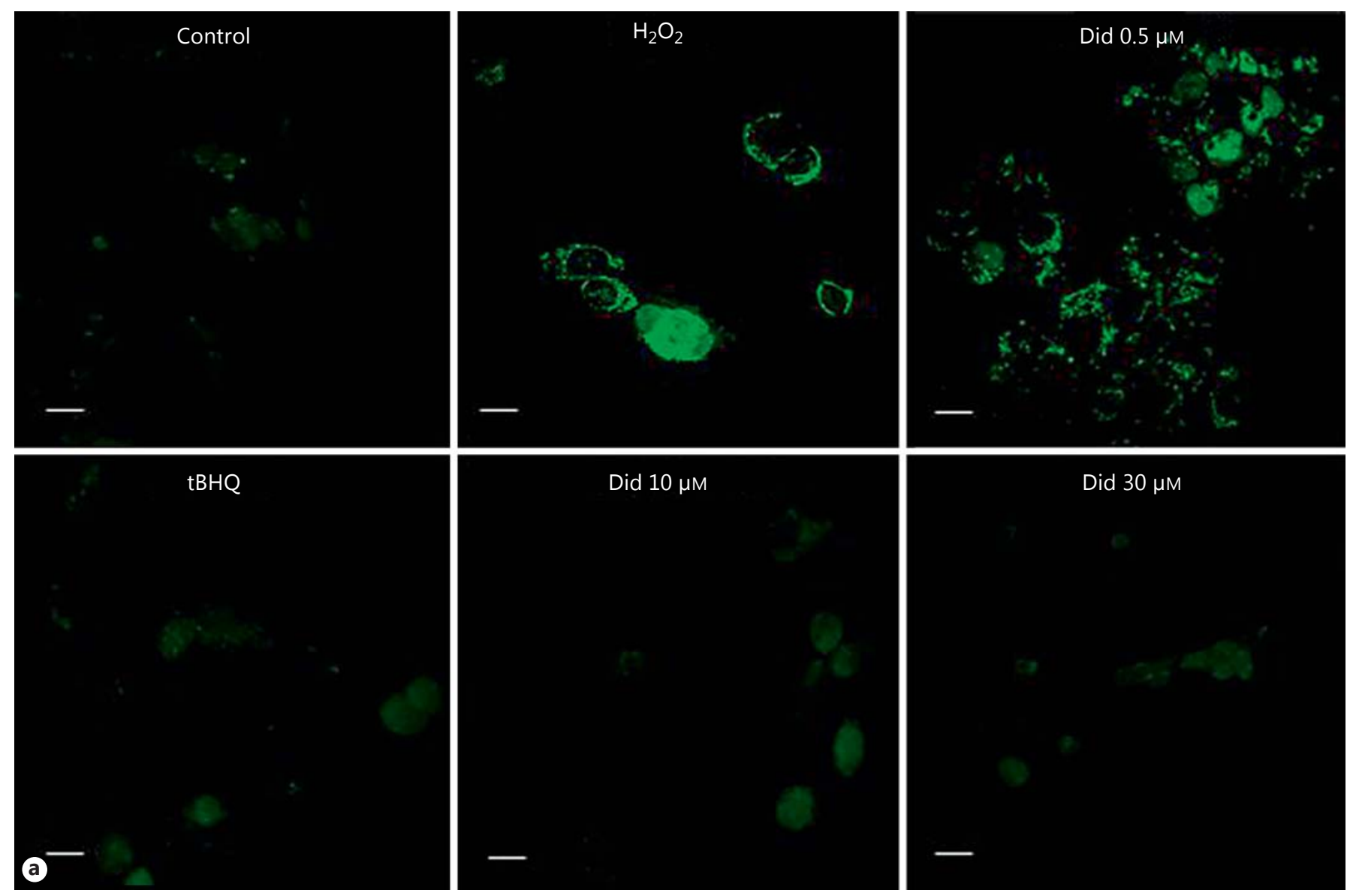

Fig. 5. Didymin suppresses $\mathrm{H}_{2} \mathrm{O}_{2}$-induced $\mathrm{ROS}$ generation in neuronal cells. a Confocal laser micrographs of neuronal cells incubated for $24 \mathrm{~h}$ with various concentrations of didymin after induction of oxidative stress $\left(\mathrm{H}_{2} \mathrm{O}_{2}\right.$ for $\left.24 \mathrm{~h}\right)$. $\mathrm{tBHQ}$ was used as a positive control. ROS generation was investigated using $\mathrm{H}_{2} \mathrm{DCF}-\mathrm{DA}$, which is deacetylated in cells, and in the presence of ROS, produced during oxidative stress, the reduced FITC compound (DCF) is oxidized and emits bright green fluorescence. Scale bar $=20 \mu \mathrm{m}$. b Quantitative analysis of fluorescence intensity of DCF produced in neuronal cells incubated with various concentrations of didymin after induction of oxidative stress $\left(\mathrm{H}_{2} \mathrm{O}_{2}\right.$ for $\left.24 \mathrm{~h}\right)$. The values expressed as average \pm SD are the means of 5 experiments and statistically significant data were evaluated according to ANOVA followed by the Bonferroni t test. ${ }^{*} \mathrm{p}<0.05$ vs. control, samples treated with didymin at a concentration of 1, 5, 10 and $30 \mu \mathrm{M}$.

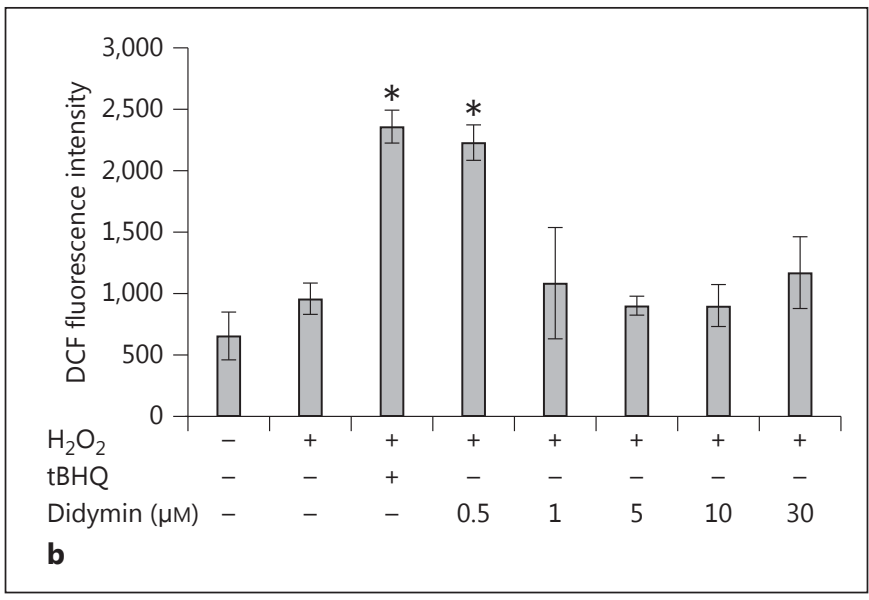

with $\mathrm{H}_{2} \mathrm{O}_{2}$ expressed both $\mathrm{PI}$ and Annexin $\mathrm{V}$ as evidenced by the intense red and green fluorescence, respectively, which clearly demonstrates that cells are in the later stages of apoptosis after $\mathrm{H}_{2} \mathrm{O}_{2}$ treatment (fig. 8a). Didymin administration caused both the lack of red staining related to PI expression and a gradual decrease in green

fluorescent intensity related to Annexin V expression. Quantitative confocal microscopy data revealed a peak of fluorescence intensity for Annexin V and PI after treatment with $\mathrm{H}_{2} \mathrm{O}_{2}$ as a result of apoptosis induction (fig. $8 \mathrm{~b}$ ). The antioxidant agent at concentrations of 0.5 and $1 \mu \mathrm{M}$ was not able to restore the redox balance within the cells. 


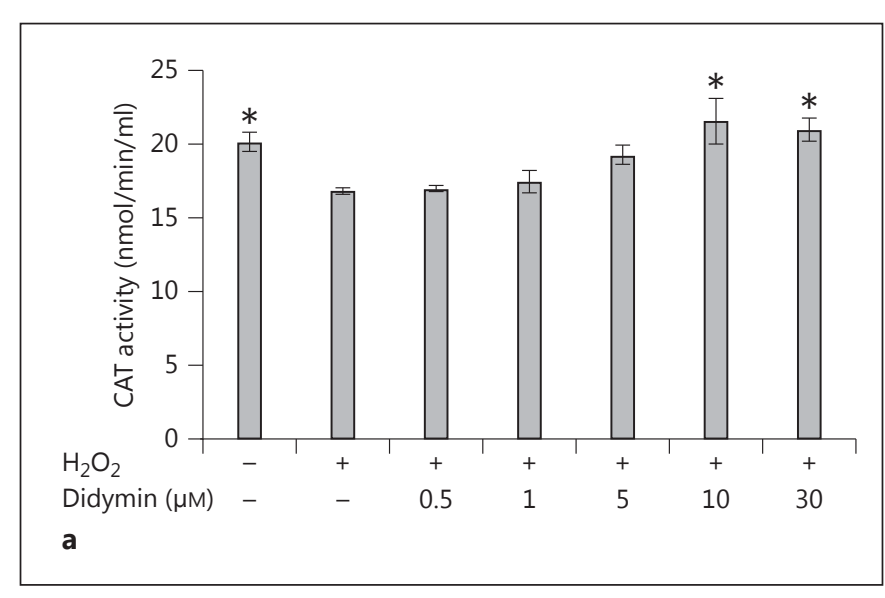

Fig. 6. Didymin promotes endogenous antioxidant defense in neuronal cells under oxidative stress $\left(\mathrm{H}_{2} \mathrm{O}_{2}\right.$ for $\left.24 \mathrm{~h}\right)$. CAT (a), SOD (b) and GPx (c) activities were determined by the commercially available assays. The values expressed as average \pm SD are the means of 5 experiments and statistically significant data were evaluated according to ANOVA followed by the Bonferroni t test. For CAT: ${ }^{*} \mathrm{p}<0.05$ vs. treatment with $\mathrm{H}_{2} \mathrm{O}_{2}$, didymin at a concentration of 0.5 and $1 \mu \mathrm{M}$. For SOD: ${ }^{*} \mathrm{p}<0.05$ vs. treatment with $\mathrm{H}_{2} \mathrm{O}_{2}$, didymin at a concentration of $0.5,1$ and $5 \mu \mathrm{M}$; ${ }^{\ddagger} \mathrm{p}<0.05$ vs. treatment with $\mathrm{H}_{2} \mathrm{O}_{2}$, didymin at a concentration of $0.5 \mu \mathrm{M}$. For GPx: $* \mathrm{p}<0.05$ vs. control, treatment with $\mathrm{H}_{2} \mathrm{O}_{2}$, didymin at a concentration of 0.5 and $1 \mu \mathrm{M} ;{ }^{\ddagger} \mathrm{p}<0.05$ vs. treatment with $\mathrm{H}_{2} \mathrm{O}_{2}$, didymin at a concentration of $0.5 \mu \mathrm{M}$.

With the lower concentration, although the percentage of viability was 82 and $73 \%$, respectively (fig. 4), the cells were already at an early apoptotic stage, as evidenced by the Annexin $\mathrm{V}$ fluorescence intensity that increased by $50 \%$ versus the control. The fluorescence intensity of Annexin $\mathrm{V}$ and PI significantly decreased when cells were treated with didymin in a dose range of 5-30 $\mu \mathrm{M}$ after induction of oxidative stress. Didymin reduces the level of apoptosis, both at the initial (positive Annexin V, negative PI) and at the advanced state (positive Annexin V, positive PI), to values which are close to those obtained in the control without oxidative treatment.

In order to further investigate the molecular mechanisms underlying the neuroprotective effect of didymin we investigated the activation of caspase- 3 and JNK, which have been shown to be important regulators of apoptosis. Treatment with $\mathrm{H}_{2} \mathrm{O}_{2}$ significantly increased cleaved caspase- 3 and phosphorylated JNK to $39.6 \pm 8.2$ and $95 \pm$ $6.6 \%$ of control values, respectively (fig. $9 ; \mathrm{p}<0.05$ ). However, the treatment of cells with various concentrations of
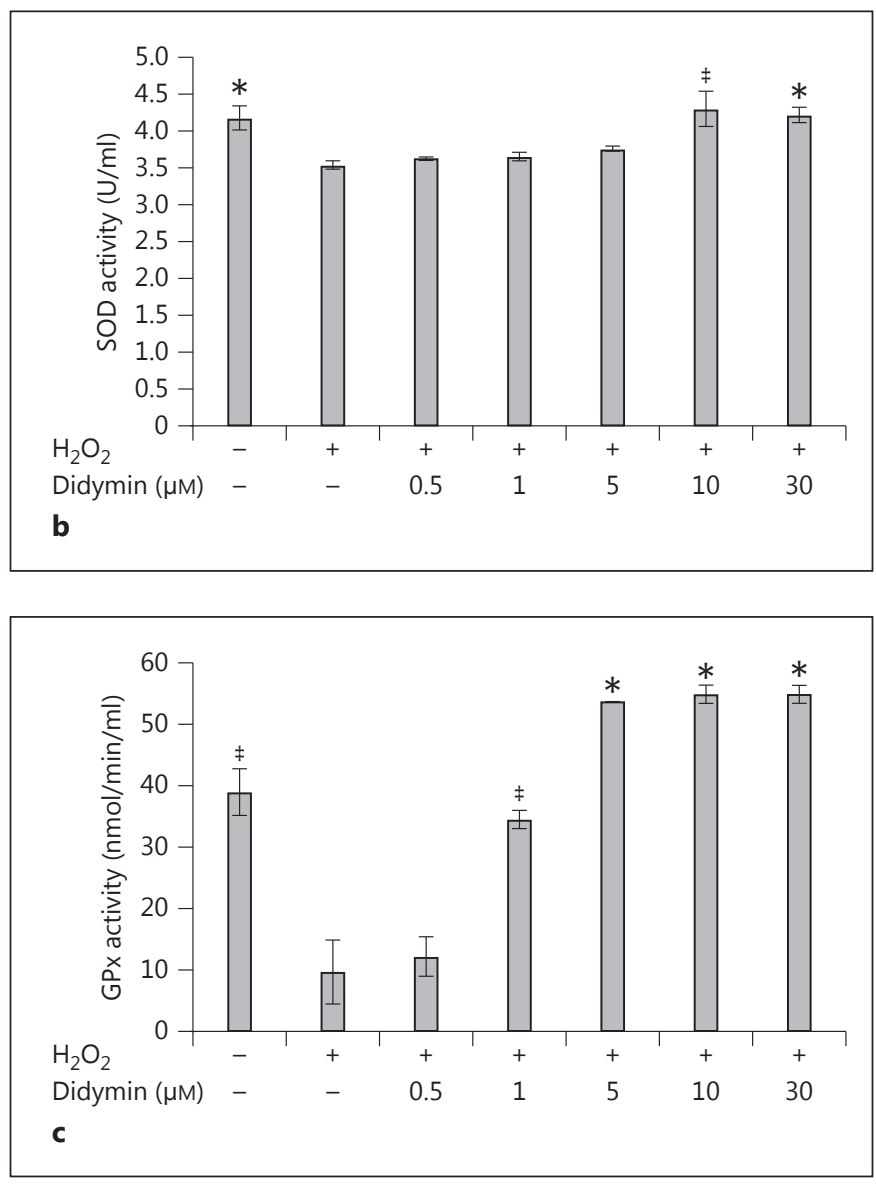

didymin for $24 \mathrm{~h}$ inhibited $\mathrm{H}_{2} \mathrm{O}_{2}$-induced caspase- 3 and $\mathrm{p}$-JNK activation in a dose-dependent manner. There was no discernible decrease in $\mathrm{p}$-JNK and caspase- 3 activation in cells treated with $0.5 \mu \mathrm{M}$ didymin. In contrast, didymin concentrations higher than $5 \mu \mathrm{M}$ significantly suppressed caspase- 3 and p-JNK activation, demonstrating the ability of this flavonoid to act as scavenger.

\section{Discussion}

This study describes for the first time the protective effect of didymin on $\mathrm{H}_{2} \mathrm{O}_{2}$-induced injury in a neuronal membrane system. The development of in vitro devices for the neuronal growth that mimic specific features of the in vivo environment is an important challenge of neuronal tissue engineering [Woerly et al., 1996; Schmidt and Leach, 2003; Zhang et al., 2005; He et al., 2009]. For this study we realized a biodegradable membrane system providing a permissive environment for neuronal outgrowth. 

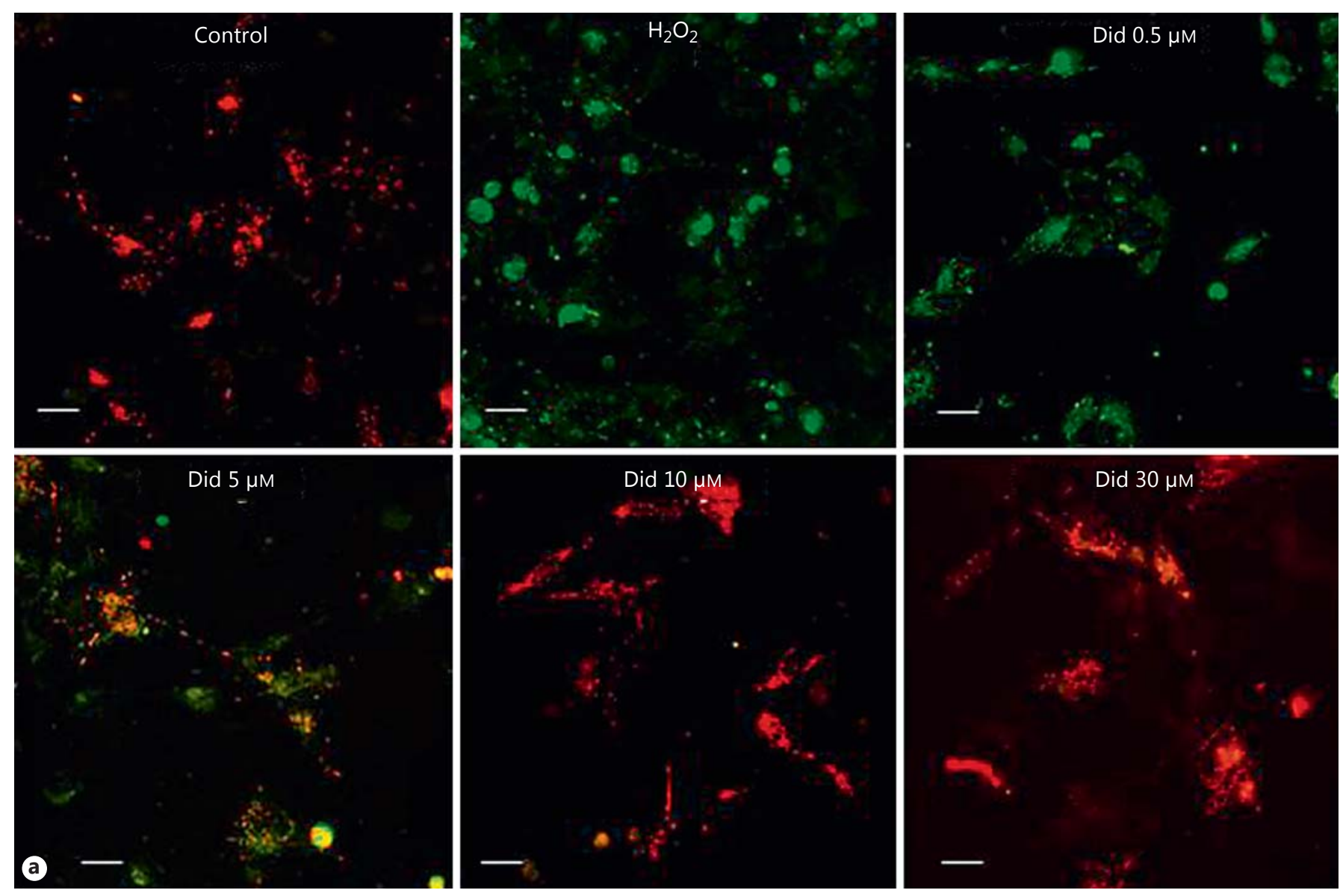

Fig. 7. Effect of didymin on $\mathrm{H}_{2} \mathrm{O}_{2}$-induced mitochondrial membrane depolarization. a Confocal laser micrographs of neuronal cells incubated for $24 \mathrm{~h}$ with various concentrations of didymin after induction of oxidative stress $\left(\mathrm{H}_{2} \mathrm{O}_{2}\right.$ for $\left.24 \mathrm{~h}\right)$. Scale bar $=20$ $\mu \mathrm{m}$. b Quantitative analysis of $\mathrm{H}_{2} \mathrm{O}_{2}$-induced mitochondrial membrane depolarization as detected by the ratio between JC-1 red and green fluorescence intensity. The values expressed as average \pm SD are the means of 5 experiments and statistically significant data were evaluated according to ANOVA followed by the Bonferroni t test. ${ }^{*} \mathrm{p}<0.05$ vs. control, treatment with $\mathrm{H}_{2} \mathrm{O}_{2}$, didymin at a concentration of $0.5,1$ and $5 \mu \mathrm{M} ;{ }^{\ddagger} \mathrm{p}<0.05$ vs. treatment with $\mathrm{H}_{2} \mathrm{O}_{2}$, didymin at a concentration of 0.5 and $1 \mu \mathrm{M}$.

In particular, the differentiation of SH-SY5Y cells in culture on PCL membranes was demonstrated by investigating not only the morphological behavior but also the expression of specific neuronal markers. Cells were able to adhere to and grow on PCL membranes by developing a neuron-like phenotype that was characterized by a spin-

dle-like cell somata and extensive neuritis outgrowth. This neuron-like morphology is similar to that described by others [Clagett-Dame et al., 2006; Cheung et al., 2009]. Moreover, the in vitro reconstruction of the neuronal network obtained in this work on PCL membranes clearly indicates the neuronal differentiation, which is in ac- 

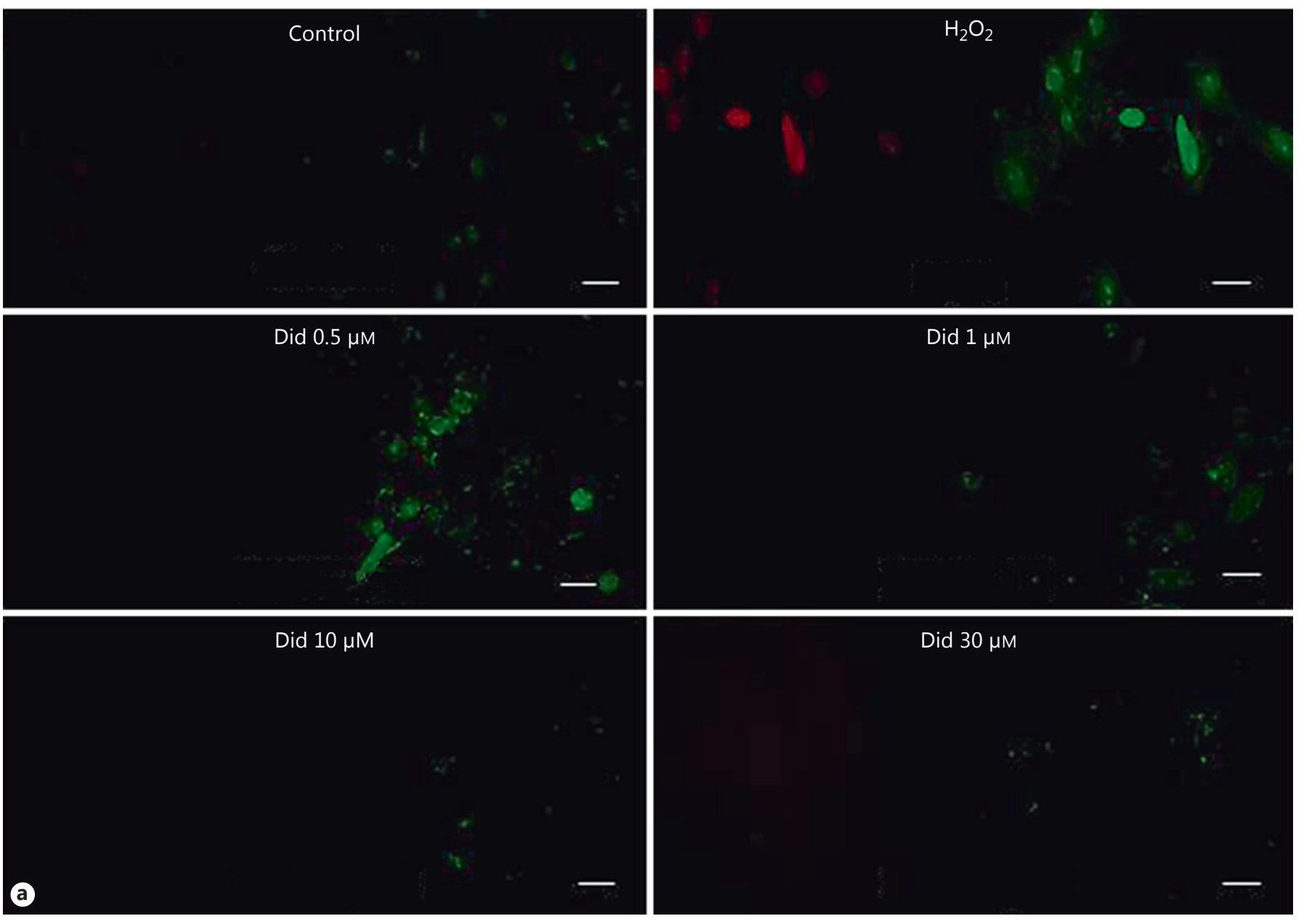

Fig. 8. Didymin suppresses $\mathrm{H}_{2} \mathrm{O}_{2}$-induced apoptosis in neuronal cells. a Confocal laser micrographs of cells incubated with various concentrations of didymin after induction of oxidative stress $\left(\mathrm{H}_{2} \mathrm{O}_{2}\right.$ for $\left.24 \mathrm{~h}\right)$. The cells were stained with Annexin V-FITC (green) and PI (red). b Fluorescence average intensity of Annexin V-FITC $(\bullet)$ and PI ( $\boldsymbol{\square})$ of cells incubated with various concentrations of didymin after induction of oxidative stress. The values expressed as average \pm SD are the means of 5 experiments and statistically significant data were evaluated according to ANOVA followed by the Bonferroni t test. For Annexin V: ${ }^{*} \mathrm{p}<0.05$ vs. control, treatment with didymin at a concentration of 5,10 and $30 \mu \mathrm{M}$; ${ }^{\ddagger} \mathrm{p}<0.05$ vs. all treatments. For PI: ${ }^{+} \mathrm{p}<0.05$ vs. all treatments.

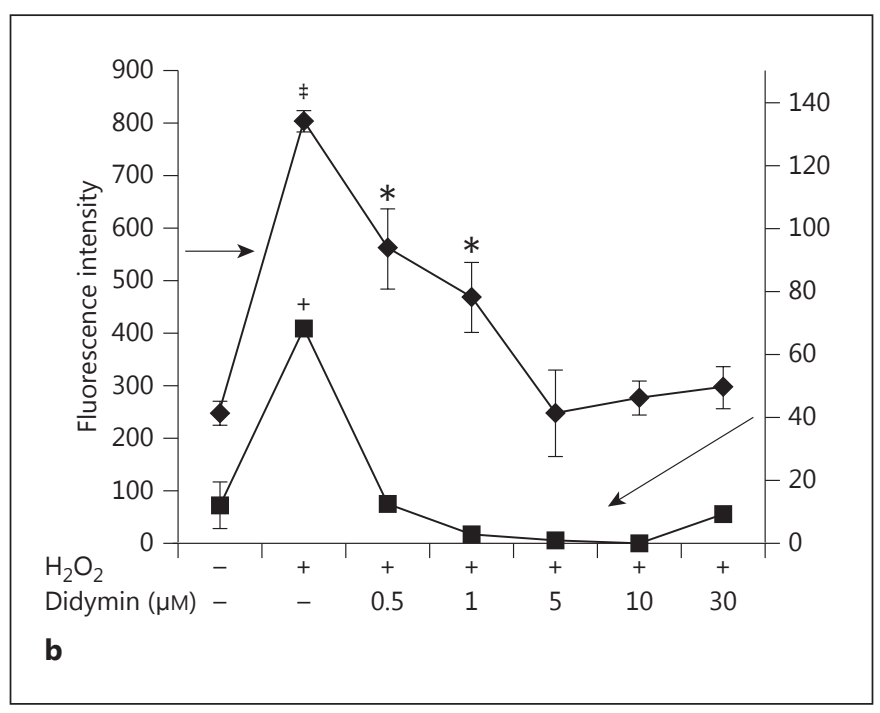

Neuroprotective Effect of Didymin 


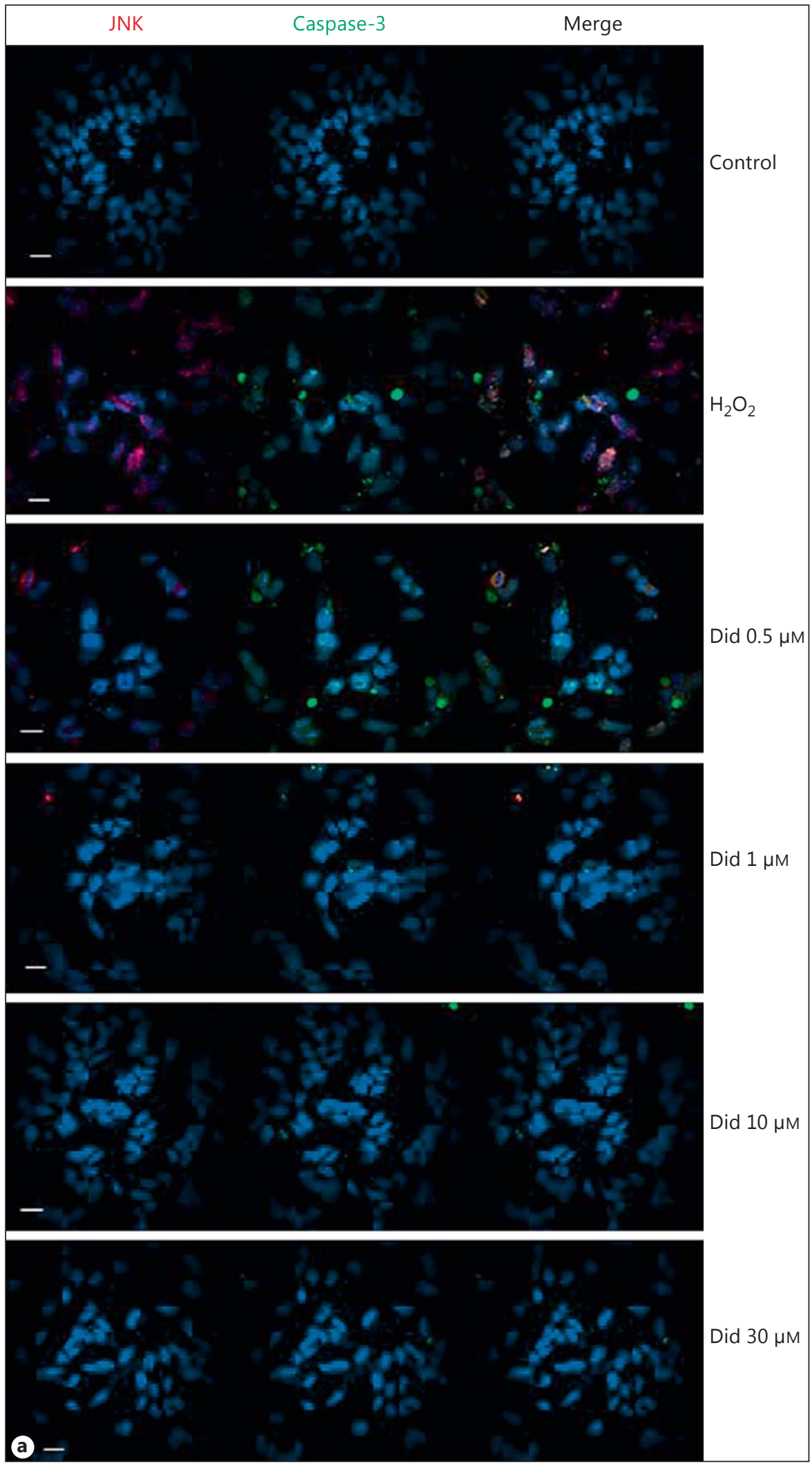

Fig. 9. Effect of didymin on p-JNK and caspase-3 activity of cells after induction of oxidative stress $\left(\mathrm{H}_{2} \mathrm{O}_{2}\right.$ for $\left.24 \mathrm{~h}\right)$. a Confocal laser micrographs of neuronal cells incubated for $24 \mathrm{~h}$ with various concentrations of didymin after induction of oxidative stress. Cells were stained for p-JNK (red), caspase-3 (green) and nuclei (blue). Scale bar $=20 \mu \mathrm{m}$.

a -

Morelli/Piscioneri/Salerno/Al-Fageeh/ Drioli/De Bartolo 


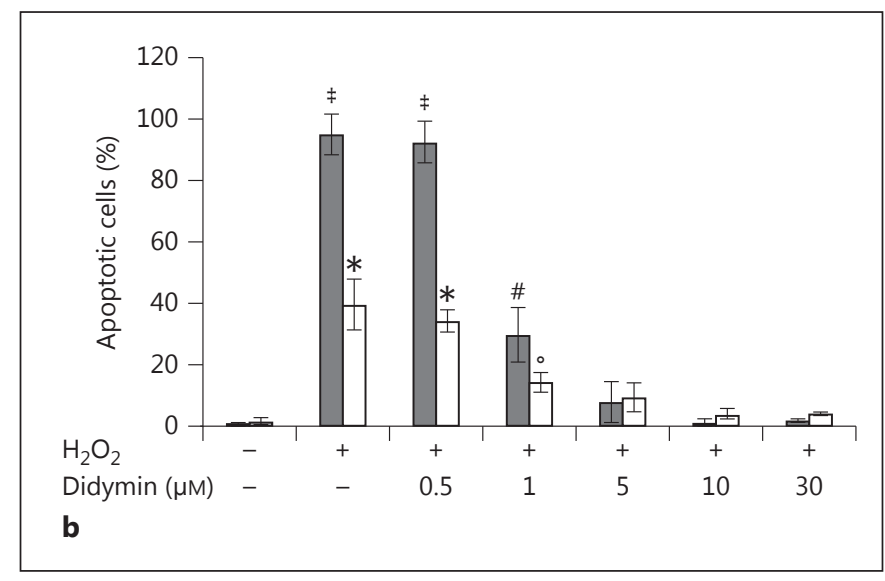

Fig. 9. Effect of didymin on p-JNK and caspase-3 activity of cells after induction of oxidative stress $\left(\mathrm{H}_{2} \mathrm{O}_{2}\right.$ for $\left.24 \mathrm{~h}\right)$. b Quantitative analysis of p-JNK (full bar) and caspase-3 (empty bar) activity. The percentage of apoptotic cells was calculated by the ratio of apoptotic nuclei (caspase-3-positive nuclei and p-JNK-positive nuclei) over total nuclei (DAPI-stained nuclei) counted at different culture conditions. The values expressed as average \pm SD are the means of 5 experiments and data statistically significant were evaluated according to ANOVA followed by the Bonferroni t test. For p-JNK: ${ }^{*} \mathrm{p}<0.05$ vs. control, treatment with didymin at a concentration of $1,5,10$ and $30 \mu \mathrm{M} ;{ }^{\circ} \mathrm{p}<0.05 \mathrm{vs}$. control, treatment with didymin at a concentration of 10 and $30 \mu \mathrm{M}$. For caspase- 3 : $^{\ddagger} \mathrm{p}<$ 0.05 vs. control, treatment with didymin at a concentration of 1,5 , 10 and $30 \mu \mathrm{M} ;{ }^{\#} \mathrm{p}<0.05$ vs. control, treatment with didymin at a concentration of 5,10 and $30 \mu \mathrm{M}$.

cordance with our previous findings [De Bartolo et al., 2008; Morelli et al., 2010, 2012b].

To confirm that the observed morphological features were actually resulting from the neuronal differentiation of SH-SY5Y cells, the expression of specific neuronal markers, $\beta I I I-t u b u l i n$ and synaptophysin, were investigated by immunocytochemical analysis. $\beta$ III-Tubulin is a cytoskeletal protein typical of the soma and neuronal processes and its expression seems to increase during axonal outgrowth [Carré et al., 2002]. To visualize $\beta I I I-t u b u l i n$ we used an anti- $\beta$ III-tubulin antibody, TuJ 1 , which reacts exclusively with homologous mammalian $\beta$-tubulin isotypes, collectively referred to as $\beta$ III, which is initially expressed at the onset of neural differentiation and is the only $\beta$-tubulin present in the mammalian brain whose expression is neuron specific [Lee et al., 1990].

Synaptophysin is the most abundant integral membrane protein of synaptic vesicles [Thiel, 1993] and it plays a number of diverse roles in synaptic function [Kwon and Chapman, 2011]. In this study, the expression and the distributions of these specific neuronal markers demonstrated that neuronal processes ramify, branch and form synapses with other neurons. These findings clearly indicate that the correct neuronal differentiation had taken place in the PCL membrane system, in accordance with recent work in which PCL-based membranes for their morphological, physicochemical and mechanical properties were able to support and improve neuronal cell adhesion, proliferation and differentiation [Morelli et al., 2012a].

In the current study, this biohybrid membrane system constituted by PCL membranes and differentiated neuronal cells was used as a model system for the in vitro induction of oxidative stress (fig. 2). Several recent reports suggest that the oxidative stress might play an important role in the pathogenesis of neurodegenerative disorders. It has been recognized that ROS, such as $\mathrm{H}_{2} \mathrm{O}_{2}$, superoxide anion and hydroxyl, radically damage biological molecules, leading to apoptotic or necrotic cell death and eventually cause neurological damage, Parkinson's and Alzheimer's diseases. Therefore, removal of excess ROS or suppression of their generation by antioxidant molecules may be effective to maintain cellular redox homeostasis and to protect against oxidative damage. The challenge is to induce neuroprotection or neurorescue by therapeutics that would respectively prevent or stop the progressive neurodegeneration.

In recent years there has been a growing interest in finding natural substances with neuroprotective effects, and attention has been focused on a wide array of dietary antioxidants that can scavenge free radicals and may consequently prevent inflammatory conditions, aging and neurodegenerative diseases.

Didymin is a novel, orally active and palatable flavonoid glycoside that is richly expressed in citrus fruits such as orange, lemon, mandarin and bergamot [Calabrò et al., 2004]. Previous studies have elucidated the anticancer properties of didymin and its mechanism of action [Hung et al., 2010]. Singhal et al. [2012] showed that didymin does not cause any cytotoxicity in normal cells and tissues or any overt toxicity in mice, whereas it exhibits antiproliferative, antiangiogenic and anticancer effects in in vitro cell cultures and in vivo mice xenograft models of neuroblastomas. In agreement with this study, we did not observe any toxic effect of the molecule on the differentiated neuronal cells (fig. 3).

For the first time, we investigated the antioxidant activity of didymin and we evaluated its neuroprotective effect against $\mathrm{H}_{2} \mathrm{O}_{2}$-induced damage in normal differentiated neuronal cells. Furthermore, this study also aimed at evaluating the potential capabilities of this flavonoid to induce 
recovery from oxidative damage and the eventual restoration of normal cellular conditions in neuronal cells.

$\mathrm{H}_{2} \mathrm{O}_{2}$ was used to generate free radicals in neuronal cells because it has been extensively used as an inducer of oxidative stress in in vitro models. Several studies have shown that $\mathrm{H}_{2} \mathrm{O}_{2}$ induces neuronal cell death through the necrotic and/or apoptotic pathway depending on its concentration and exposure time [Chen et al., 2009].

According to the literature, we used $\mathrm{H}_{2} \mathrm{O}_{2}$ to induce oxidative stress, evoking a dose-dependent cell damage and viability loss confirmed in our data by an increase of 3- and 6-fold in the expression of Annexin V and PI staining, respectively (fig. 8), as a result of cell death induced by $\mathrm{H}_{2} \mathrm{O}_{2}$ treatment through mechanisms of apoptosis and necrosis. The present study has attempted to determine the neuroprotective effect of didymin when it is administered after the induction of cell damage (neurorescue). In order to have an in vitro model of oxidative stress, neuronal cells after 7 days of culture in the PCL membrane system were initially subjected to $\mathrm{H}_{2} \mathrm{O}_{2}$ treatment before the administration of didymin for the next $24 \mathrm{~h}$. In spite of the high percentage of cell death, administration of didymin significantly attenuated cell death and reduced the intracellular ROS levels. As a positive control we used tBHQ since it is known as a strong inducer of phase II detoxification enzymes which have antioxidative functions [Hara et al., 2003; Li et al., 2012]. Lee et al. [2001] demonstrated that the treatment with $\mathrm{tBHQ}$ prevented $\mathrm{H}_{2} \mathrm{O}_{2}$-induced apoptosis and induced many genes associated with resistance against oxidative stress in neuronal cells. How didymin is able to scavenge $\mathrm{H}_{2} \mathrm{O}_{2}$-induced ROS production in a similar trend observed with the reference antioxidant molecule $\mathrm{tBHQ}$ is shown for the first time in this work. In particular, the comparative study performed by using tBHQ clearly supports both neuroprotective and antioxidant actions mediated by didymin.

One possible explanation for the effect of didymin concerns its chemical structure. It could rescue cells from oxidative damage directly scavenging free radicals by hydrogen atom donation and/or indirectly by activation of antioxidant enzymes [Ishige et al., 2001].

Our results indicate that the neuroprotection by didymin was due to the enhancement of SOD, GPx and CAT activities (fig. 6), allowing the cells to keep or to improve their intrinsic antioxidant mechanisms since GPx plays a predominant role in removing the excess of free radicals and is a major defense system against oxidative threat in the brain [Khan et al., 2010], and SOD and CAT are two important antioxidant enzymes. It has been shown that SOD has the ability to transform superoxide anions to
$\mathrm{H}_{2} \mathrm{O}_{2}$, which is subsequently scavenged by CAT [Xiao et al., 2008]. In our study, the treatment with didymin restores the concerted action between SOD and CAT and GPx that avoids the accumulation of $\mathrm{H}_{2} \mathrm{O}_{2}$, which is responsible for ROS production and cell impairment. These results clearly show that didymin displays antioxidant properties.

Since suppression of apoptosis may be a useful strategy for neuroprotection [Guo et al., 2005], we next investigated whether didymin was able to protect neuronal cells from $\mathrm{H}_{2} \mathrm{O}_{2}$-induced apoptosis. Recently, the loss of the MMP has been identified as the first step in the apoptotic process. Moreover, oxidative stress is accompanied by a large increase in intracellular calcium levels and has been linked to a decrease in MMP [Brookes et al., 2004], which is widely considered as an indicator of mitochondrial functionality. In this paper, we have demonstrated that didymin treatment reversed the $\mathrm{H}_{2} \mathrm{O}_{2}$-induced decrease of MMP in a dose-dependent manner (fig. 7). Thus, it is suggested that the protection of didymin may be related to the recovery of mitochondrial bioenergetics and functions.

Our results demonstrate that didymin inhibits both apoptotic and necrotic processes in a dose-dependent manner. Through the inhibition of the apoptotic process, didymin acts as scavenger blocking the downstream signaling pathway due to $\mathrm{H}_{2} \mathrm{O}_{2}$-induced cellular ROS. Cells that are not able to repair damage induced by oxidative stress may enter an apoptotic state. Considering that premature apoptosis is implicated in the neurodegeneration pathology [Okouchi et al., 2007], antioxidants might block ROS-triggered apoptosis, contributing to therapies against neurodegeneration.

There is abundant evidence that flavonoids are effective in blocking oxidant-induced neuronal injury by modulating a number of protein kinase signaling cascades, such as the mitogen-activated protein kinase signaling pathways [Williams et al., 2004]. Inhibitory or stimulatory actions of these pathways are likely to profoundly affect neuronal function by altering the phosphorylation state of target molecules, leading to changes in caspase activity [Williams et al., 2004]. For example, flavonoids have been observed to block oxidative-induced neuronal damage by preventing the activation of caspase-3, providing evidence in support of their potent antiapoptotic action [Schroeter et al., 2001; Spencer et al., 2001]. The flavanol epicatechin also protects neurons against oxidative damage via a mechanism involving the suppression of JNK, and downstream partners, c-Jun and pro-caspase-3 [Schroeter et al., 2001]. The flavone baicalein has been shown to significantly inhibit 6-hydroxydo- 
pamine-induced JNK activation and neuronal cell death, and quercetin may suppress JNK activity and apoptosis induced by $\mathrm{H}_{2} \mathrm{O}_{2}$ [Wang et al., 2002].

To gain insight into the mechanism underlying the didymin-induced neuroprotection, we analyzed the effect of didymin on the expression of two important apoptotic markers, namely caspase- 3 and JNK. JNK is one of the main stress-responsive kinases and has been implicated in oxidative stress-induced apoptosis [Deng et al., 2003]. Several lines of evidence suggest that JNK is an important mediator in oxidative stress-induced apoptotic cell death.

During the execution of the apoptotic cascade, activated caspase-3 releases sterol regulatory element binding protein from the membrane in a proteolytic reaction that is distinct from their normal sterol-dependent activation. Caspase- 3 cleaves and activates sterol regulatory element binding proteins between the basic helix-loophelix leucine zipper domain and the membrane attachment domain. Caspase- 3 also cleaves and activates caspase-6, caspase- 7 and caspase-9. For this reason, the overexpression of activated caspase- 3 can result in apoptosis [Jaeschke et al., 1998]. Caspase-3, when proteolytically activated, cleaves several specific cellular proteins, leading to the irreversible characteristic morphological and biochemical changes of apoptosis. It plays a major role in the disassembly of the nucleus by processing several nuclear substrates. We observed that active-caspase- 3 expression was much higher in the samples after $\mathrm{H}_{2} \mathrm{O}_{2}$-induced oxidative stress, and its localization was nuclear (fig. 9a). The nuclear translocation of active caspase-3 leads to the induction of DNA fragmentation. Our data demonstrate that didymin administration to the cells causes a strong decrease of both activation and expression of caspase- 3 and $\mathrm{p}$-JNK, suggesting that flavonoid could suppress the oxidative stress-induced apoptosis process by inhibition of p-JNK and caspase-3. Therefore, these results suggest the possibility of JNK and caspase- 3 involvement in the neurorescue paradigm.

In summary, the findings of this study suggest that didymin decreased intracellular ROS generation and restored decreased antioxidant enzyme activities by stimulating superoxide dismutase, CAT and GPx activity. These results clearly demonstrate the antioxidant properties and the neuroprotective effect of didymin in neuronal cells which were previously insulted with $\mathrm{H}_{2} \mathrm{O}_{2}$. In conclusion, this flavonoid reverses the damage caused by oxidative treatment allowing the cell to return to its homeostasis.

These experimental results already give the first insight of the specific effects of didymin, although further investigation of the molecular mechanisms responsible for the neuroprotective action is necessary. On the basis of these results, this antioxidant agent could be used as a potential therapeutic candidate for treating neurodegenerative disease associated with oxidative stress (Parkinson's disease, Alzheimer's disease, Huntington's disease, amyotrophic lateral sclerosis), or employed in physiological conditions as an antiaging molecule.

\section{Acknowledgements}

The authors acknowledge King Abdulaziz City for Science and Technology (KACST), the Kingdom of Saudi Arabia, for funding the project 'Membrane Systems in Regenerative Medicine, Tissue Engineering and Biotechnology' (KACST-ITM 03).

\section{References}

Barber, C.S., R.J. Mead, P.J. Shaw (2006) Oxidative stress in ALS: a mechanism of neurodegeneration and a therapeutic target. Biochim Biophys Acta 1762: 1051-1067.

Brookes, P.S., Y. Yoon, J.L. Robotham, M.W. Anders, S.S. Sheu (2004) Calcium, ATP, and ROS: a mitochondrial love-hate triangle. Am J Physiol Cell Physiol 287: C817-C833.

Calabrò, M.L., V. Galtieri, P. Cutroneo, S. Tommasini, P. Ficarra, R. Ficarra (2004) Study of the extraction procedure by experimental design and validation of a LC method for determination of flavonoids in citrus bergamia juice. J Pharm Biomed Anal 35: 349-363.

Carré, M., N. André, G. Carles, H. Borghi, L. Brichese, C. Briand, D. Braguer (2002) Tubulin is an inherent component of mitochondrial membranes that interacts with the voltage- dependent anion channel. J Biol Chem 277: 33664-33669.

Chen, C.M. (2011) Mitochondrial dysfunction, metabolic deficits, and increased oxidative stress in Huntington's disease. Chang Gung Med J 34: 135-152.

Chen, L., L. Liu, J. Yin, Y. Luo, S. Huang (2009) Hydrogen peroxide-induced neuronal apoptosis is associated with inhibition of protein phosphatase 2A and 5, leading to activation of MAPK pathway. Int J Biochem Cell Biol 41: 1284-1295.

Cheung, Y.T., W.K. Lau, M.S. Yu, C.S. Lai, S.C. Yeung, K.F. So, R.C.C. Chang (2009) Effects of all-trans-retinoic acid on human SH-SY5Y neuroblastoma as in vitro model in neurotoxicity research. Neurotoxicology 30: 127-135.
Clagett-Dame, M., E.M. McNeill, P.D. Muley (2006) Role of all-trans retinoic acid in neurite outgrowth and axonal elongation. J Neurobiol 66: 739-756.

De Bartolo, L., M. Rende, S. Morelli, G. Giusi, S. Salerno, A. Piscioneri, A. Gordano, A. Di Vito, M. Canonaco, E. Drioli (2008) Influence of membrane surface properties on the growth of neuronal cells isolated from hippocampus. J Membrane Sci 325: 139-149.

Deng, Y., X. Ren, L. Yang, Y. Lin, X.A. Wu (2003) JNK-dependent pathway is required for TNFa-induced apoptosis. Cell 115: 61-70.

Di Vito, A., G. Giusi, R. Alò, A. Piscioneri, S. Morelli, L. De Bartolo, M. Canonaco (2011) Distinct $\mathrm{aGABA}_{\mathrm{A}} \mathrm{R}$ subunits influence structural and transcriptional properties of CA1 hippocampal neurons. Neurosci Lett 496: 106-110. 
Giusi, G., R.M. Facciolo, M. Rende, R. Alo, A. Di Vito, S. Salerno, S. Morelli, L. De Bartolo, E. Drioli, M. Canonaco (2009) Distinct a subunits of the GABAA receptor are responsible for early hippocampal silent neuron-related activities. Hippocampus 19: 1103-1114.

Guo, S., E. Bezard, B. Zhao (2005) Protective effect of green tea polyphenols on the SH-SY5Y cells against 9-OHDA induced apoptosis through ROS-NO pathway. Free Radic Biol Med 39: 682-695.

Halliwell, B. (2006) Oxidative stress and neurodegeneration: where are we now? J Neurochem 97: 1634-1658.

Hara, H., M. Ohta, K. Ohta, S. Kuno, T. Adachi (2003) Increase of antioxidative potential by tert-butylhydroquinone protects against cell death associated with 6-hydroxydopamineinduced oxidative stress in neuroblastoma SH-SY5Y cells. Mol Brain Res 119: 125-131.

He, Q., T. Zhang, Y. Yang, F. Ding (2009) In vitro biocompatibility of chitosan-based materials to primary culture of hippocampal neurons. J Mater Sci Mater Med 20: 1457-1466.

Hermsdorff, H.H., K.B. Barbosa, A.C. Volp, B. Puchau, J. Bressan, M.Á. Zulet, J.A. Martínez (2012) Vitamin C and fibre consumption from fruits and vegetables improves oxidative stress markers in healthy young adults. $\mathrm{Br} \mathrm{J}$ Nutr 107: 1119-1127.

Hung, J.Y., Y.L. Hsu, Y.C. Ko, Y.M. Tsai, C.J. Yang, M.S. Huang, P.L. Kuo (2010) Didymin, a dietary flavonoid glycoside from citrus fruits, induces Fas-mediated apoptotic pathway in human non-small-cell lung cancer cells in vitro and in vivo. Lung Cancer 68: 366-374.

Ishige, K., D. Schubert, Y. Sagara (2001) Flavonoids protect neuronal cells from oxidative stress by three distinct mechanisms. Free Radic Biol Med 30: 433-446.

Jaeschke, H., M.A. Fisher, J.A. Lawson, C.A. Simmons, A. Farhood, D.A. Jones (1998) Activation of caspase 3 (CPP32)-like protease is essential for TNF- $\alpha$-induced hepatic parenchymal cell apoptosis and neutrophil-mediated necrosis in a murine endotoxin shock model. J Immunol 160: 3480-3486.

Kaplan, D.R., K. Matsumoto, E. Lucarelli, C.J. Thiele (1993) Induction of Trk B by retinoic acid mediates biologic responsiveness to BDNF and differentiation of human neuroblastoma cells. Neuron 11: 321-331.

Khan, M.M., M.N. Hoda, T. Ishrat, A. Ahmad, M.B. Khan, G. Khuwaja, S.S. Raza, M.M. Safhi, F. Islam (2010) Amelioration of 1-methyl4-phenyl-1,2,3,6-tetrahydropyridine-induced behavioural dysfunction and oxidative stress by Pycnogenol in mouse model of Parkinson's disease. Behav Pharmacol 21: 563-571.

Klein, CL, M. Scholl, A. Maelicke (1999) Neuronal networks in vitro: formation and organization on biofunctionalized surfaces. J Mater Sci Mater Med 10: 721-727.

Kwon, S.E., E.R. Chapman (2011) Synaptophysin regulates the kinetics of synaptic vesicle endocytosis in central neurons. Neuron 70: 847854.
Lee, H.J., H.S. Cho, E. Park, S. Kim, S.Y. Lee, C.S. Kim, D.K. Kim, S.J. Kim, H.S. Chun (2008) Rosmarinic acid protects human dopaminergici neuronal cells against hydrogen peroxide-induced apoptosis. Toxicology 250: 109115.

Lee, J.M., J.M. Hanson, W.A. Chu, J.A. Johnson (2001) Phosphatidylinositol 3-kinase, not extracellular signal-regulated kinase, regulates activation of the antioxidant-responsive element in IMR-32 human neuroblastoma cells. J Biol Chem 276: 20011-20016.

Lee, M.K., L.I. Rebhun, A. Frankfurter (1990) Posttranslational modification of class III $\beta$-tubulin. Proc Natl Acad Sci 87: 7195-7199.

Li, H., S. Wu, Z. Wang, W. Lin, C. Zhang, B. Huang (2012) Neuroprotective effects of tertbutylhydroquinone on paraquat-induced dopaminergic cell degeneration in $\mathrm{C} 57 \mathrm{BL} / 6$ mice and in PC12 cells. Arch Toxicol 86: 1729-1740.

Meiyanto, E., A. Hermawan, Anindyajati (2012) Natural products for cancer-targeted therapy: citrus flavonoids as potent chemopreventive agents. Asian Pac J Cancer Prev 13: 427 436.

Morelli, S., A. Piscioneri, A. Messina, S. Salerno, M. B. Al-Fageeh, E. Drioli, L. De Bartolo (2012a) Neuronal growth and differentiation on biodegradable membranes. J Tissue Eng Regen Med, Epub ahead of print.

Morelli, S., A. Piscioneri, S. Salerno, M. Rende, C. Campana, F. Tasselli, A. Di Vito, G. Giusi, M. Canonaco, E. Drioli, L. De Bartolo (2012b). Flat and tubular membrane systems for the reconstruction of hippocampal neuronal network. J Tissue Eng Regen Med 6: 299-313.

Morelli, S., A. Piscioneri, S. Salerno, F. Tasselli, A. Di Vito, G. Giusi, M. Canonaco, E. Drioli, L. De Bartolo (2012c) PAN hollow fiber membranes elicit functional hippocampal neuronal network. J Mater Sci Mater Med 23: 149-156.

Morelli, S., S. Salerno, A. Piscioneri, B.J. Papenburg, A. Di Vito, G. Giusi, M. Canonaco, D. Stamatialis, E. Drioli, L. De Bartolo (2010) Influence of micro-patterned PLLA membranes on outgrowth and orentation of hippocampal neurites. Biomaterials 31: 7000-7011.

Okouchi, M., O. Ekshyyan, M. Maracine, T.Y. Aw (2007) Neuronal apoptosis in neurodegeneration. Antioxid Redox Signal 9: 1059-1096.

Pahlman, S., J.C. Hoehner, E. Nånberg, F. Hedborg, S. Fagerstrom, C. Gestblom, I. Johansson, U. Larsson, E. Lavenius, E. Ortoft, H. Soderholm (1995) Differentiation and survival influences of growth factors in human neuroblastoma. Eur J Cancer 31A: 453-458.

Schmidt, C.E., J.B. Leach (2003) Neural tissue engineering: strategies for repair and regeneration. Annu Rev Biomed Eng 5: 293-347.

Schroeter, H., J.P. Spencer, C. Rice-Evans, R.J. Williams (2001) Flavonoids protect neurons from oxidized low-density-lipoprotein-induced apoptosis involving c-Jun N-terminal kinase (JNK), c-Jun and caspase-3. Biochem J 358: 547-557.
Singhal, J., L.D. Nagaprashantha, R. Vatsyayan, Ashutosh, S. Awasthi, S.S. Singhal (2012) Didymin induces apoptosis by inhibiting $\mathrm{N}$ Myc and upregulating RKIP in neuroblastoma. Cancer Prev Res 5: 473-483.

Smith, M.A., G. Casadeus, J.A. Joseph, G. Perry (2002) Amyloid- $\beta$ and $\tau$ serve antioxidant functions in the aging and Alzheimer brain. Free Radical Biol Med 33: 1194-1199.

Spagnuolo, C., M. Russo, S. Bilotto, I. Tedesco, B. Laratta, G.L. Russo (2012) Dietary polyphenols in cancer prevention: the example of the flavonoid quercetin in leukemia. Ann NY Acad Sci 1259: 95-103.

Spencer, J.P.E., H. Schroeter, A.J. Crossthwaithe, G. Kuhnle, R.J. Williams, C. Rice-Evans (2001) Contrasting influences of glucuronidation and O-methylation of epicatechin on hydrogen peroxide-induced cell death in neurons and fibroblasts. Free Radic Biol Med 31: 1139-1146.

Thiel, G. (1993) Synapsin I, synapsin II, and synaptophysin: marker proteins of synaptic vesicles. Brain Pathol 3: 87-95.

Thomas, B. (2009) Parkinson's disease: from molecular pathways in disease to therapeutic approaches. Antioxidants Redox Sign 11: 2077 2082.

Vauzour, D., K. Vafeiadou, A.M. Rodriguez, C. Rendeiro, J.P.E. Spencer (2008) The neuroprotective potential of flavonoids: a multiplicity of effects. Genes Nutr 3: 115-126.

Wang, L., K. Matsushita, I. Araki, M. Takeda (2002) Inhibition of c-Jun N-terminal kinase ameliorates apoptosis induced by hydrogen peroxide in the kidney tubule epithelial cells (NRK-52E). Nephron 91: 142-147.

Wang, W., W. Huang, L. Li, H. Ai, F. Sun, C. Liu, Y. An (2008) Morroniside prevents peroxideinduced apoptosis by induction of endogenous glutathione in human neuroblastoma cells. Cell Mol Neurobiol 28: 293-305.

Williams, R.J., J.P. Spencer, C. Rice-Evans (2004) Flavonoids: antioxidants or signalling molecules? Free Radic Biol Med 36: 838-849.

Woerly, S., G.W. Plant, A.R. Harvey (1996) Neural tissue engineering: from polymer to biohybrid organs. Biomaterials 17: 301-310.

Xiao, X., J. Liu, J. Hu, X. Zhu, H. Yang, C. Wang, Y. Zhang (2008) Protective effects of protopine on hydrogen peroxide-induced oxidative injury of PC12 cells via $\mathrm{Ca}^{2+}$ antagonism and antioxidant mechanisms. Eur J Pharmacol 591: 21-27.

Yang, I.H., C.C. Co, C.C. Ho (2005) Alteration of human neuroblastoma cell morphology and neurite extension with micropatterns. Biomaterials 26: 6599-6609.

Zhang, N., H. Yan, X. Wen (2005) Tissue-engineering approaches for axonal guidance. Brain Res Rev 49: 48-64.

Zhu, X., H.G. Lee, G. Perry, M.A. Smith (2007) Alzheimer disease, the two-hit hypothesis: an update. Biochim Biophys Acta 1772: 494-502. 